\title{
Nitrogen isotopic constraints on nutrient transport to the upper ocean
}

\author{
François Fripiat ${ }^{1,2} \llbracket$, Alfredo Martínez-García ${ }^{\circledR}{ }^{1}$, Dario Marconi ${ }^{3}$, Sarah E. Fawcett ${ }^{4,5}$, \\ Sebastian H. Kopf ${ }^{6}{ }^{6}$, Victoria H. Luu ${ }^{3}$, Patrick A. Rafter ${ }^{7}{ }^{7}$, Run Zhang, ${ }^{8}$, Daniel M. Sigman $\mathbb{1}^{3}$ and \\ Gerald H. Haug ${ }^{1}$
}

Ocean circulation supplies the surface ocean with the nutrients that fuel global ocean productivity. However, the mechanisms and rates of water and nutrient transport from the deep ocean to the upper ocean are poorly known. Here, we use the nitrogen isotopic composition of nitrate to place observational constraints on nutrient transport from the Southern Ocean surface into the global pycnocline (roughly the upper $1.2 \mathrm{~km}$ ), as opposed to directly from the deep ocean. We estimate that $62 \pm 5 \%$ of the pycnocline nitrate and phosphate originate from the Southern Ocean. Mixing, as opposed to advection, accounts for most of the gross nutrient input to the pycnocline. However, in net, mixing carries nutrients away from the pycnocline. Despite the quantitative dominance of mixing in the gross nutrient transport, the nutrient richness of the pycnocline relies on the large-scale advective flow, through which nutrient-rich water is converted to nutrient-poor surface water that eventually flows to the North Atlantic.

Tis: he ocean mitigates global warming by absorbing fossil-fuel $\mathrm{CO}_{2}$ and heat from the atmosphere ${ }^{1}$. Central to this role is the exchange of water between the deep ocean and the ocean's upper water column (that is, the pycnocline), with the latter communicating more directly with the atmosphere. This exchange also restores to the upper ocean nutrients that have been exported by the sinking of biological material ${ }^{2,3}$. Without this nutrient return path, biological productivity would eventually deplete nutrients from the pycnocline, and ocean productivity would collapse. Therefore, the rate and physical mechanisms leading to this exchange are central to global ocean fertility and its possible responses to climate change.

Much of the progress in physical oceanography over the last 50 years can be framed in terms of the effort to understand the degree to which deep water returns to the surface ocean by mixing-driven upwelling in the interior versus wind-driven upwelling at high latitudes, in the Southern Ocean in particular (Fig. 1). In the first conceptions of ocean circulation, the return of deep water to the pycnocline was by interior upwelling ${ }^{4,5}$, including at low latitudes ( $\omega_{\mathrm{D}}$ in Fig. 1a; with the subscript ' $\mathrm{D}$ ' for the deep ocean). This upwelling is induced by small-scale turbulent mixing, mostly from the breaking of internal waves, which transports heat downwards and thus increases the buoyancy of deep water ${ }^{6}$. However, observed rates of vertical mixing in the ocean interior are far lower than the rate of mixing required to yield observed deep-ocean overturning rates or sustain low-latitude biological production ${ }^{7-9}$.

Subsequent work pointed to wind-driven upwelling in the Southern Ocean, followed by subduction as Antarctic Intermediate Water (AAIW) and Subantarctic Mode Water (SAMW), as the dominant route by which water and nutrients are returned from the deep ocean to the pycnocline ${ }^{10-14}\left(\omega_{\mathrm{S}}\right.$ in Fig. 1a; with the subscript ' $S$ ' for the Southern Ocean). In the Southern Ocean, this overturning circulation is now understood to be the residual of the wind-driven Ekman transport and the largely opposing response of eddies to the baroclinic instability (that is, eddy advection) that results from it ${ }^{14}$. The contribution of the Southern Ocean surface to the global pycnocline water is widely thought to be substantial ${ }^{11,14}$, but its quantitative estimation remains subject to considerable uncertainty. In large part, this uncertainty arises from a lack of strong observational constraints, especially when only traditional physical and biogeochemical parameters are considered ${ }^{3,13}$.

Much of the uncertainty in the ocean's circulation relates to mixing. While mixing $(m)$ is thought to have first-order importance in the transport of heat, salt and biogeochemical properties, its contribution remains poorly constrained by observations ${ }^{15-17}$. Isopycnal mixing $\left(m_{\mathrm{S}}\right.$ in Fig. 1a) by mesoscale eddies between the pycnocline and its Southern Ocean ventilating region (that is, the Polar Frontal Zone (PFZ) and Subantarctic Zone (SAZ)) induces tracer fluxes by stirring properties along interior isopycnal surfaces (that is, eddy diffusion $)^{16,17}$. In the ocean interior, diapycnal mixing $\left(m_{\mathrm{D}}\right.$ in Fig. 1a) leads to exchanges of water and buoyancy between the pycnocline and the underlying deep ocean ${ }^{4-6}$.

With regard to large-scale advective and mixing fluxes, a distinction must be made between mass (that is, bulk seawater) and seawater properties (for example, the concentrations of nutrients). There is no net transfer of mass associated with mixing; however, when in the presence of property gradients, mixing induces both gross and net transports of properties which will, in turn, alter the density structure of the pycnocline and thus affect large-scale advective fluxes. Such transports occur because the water parcels experiencing mixing-associated motions in one direction have a systematically different property concentration from the parcels experiencing motions in the opposite direction. Integrated over large areas and

'Max Planck Institute for Chemistry, Mainz, Germany. ${ }^{2}$ Department of Geosciences, Environment and Society, Université Libre de Bruxelles, Brussels, Belgium. ${ }^{3}$ Department of Geosciences, Princeton University, Princeton, NJ, USA. ${ }^{4}$ Department of Oceanography, University of Cape Town, Rondebosch, South Africa. ${ }^{5}$ Marine and Antarctic Research Centre for Innovation and Sustainability (MARIS), University of Cape Town, Rondebosch, South Africa. ${ }^{6}$ Department of Geological Sciences, University of Colorado Boulder, Boulder, CO, USA. ${ }^{7}$ Department of Earth System Sciences, University of California, Irvine, CA, USA. ${ }^{8}$ College of Ocean and Earth Sciences, Xiamen University, Xiamen, China. ${ }^{凶}$ e-mail: francois.fripiat@ulb.be 


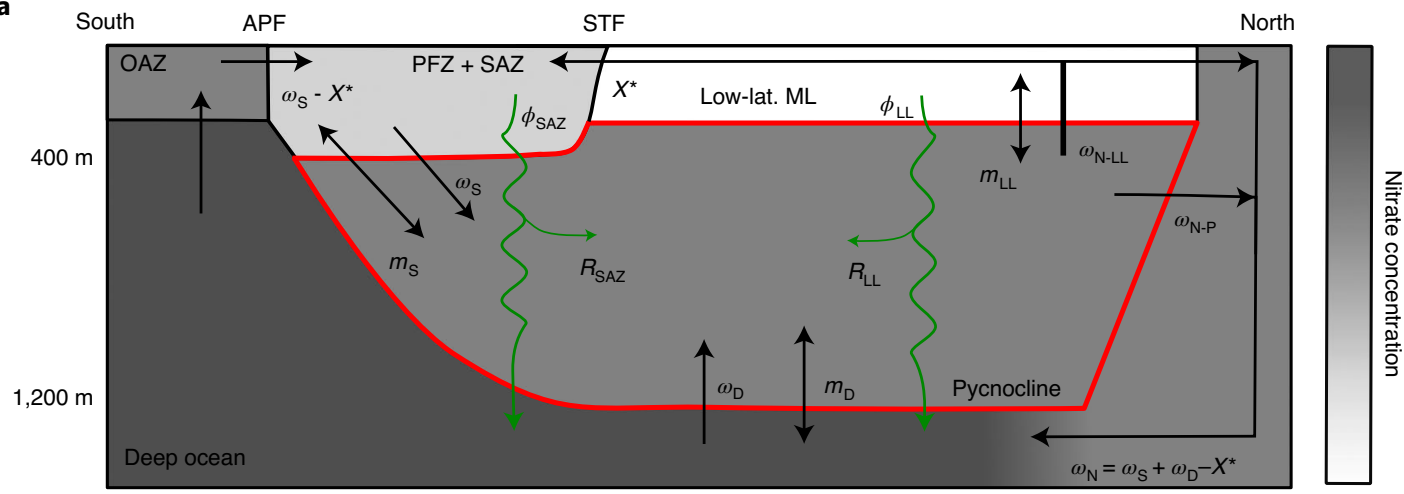

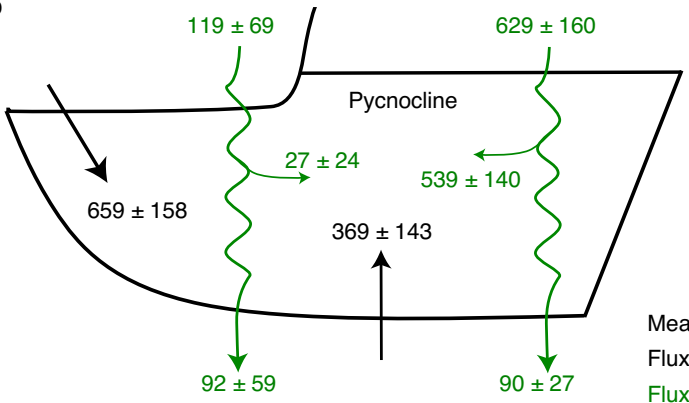
$597 \pm 212$
Fluxes in $\mathrm{Tg} \mathrm{N}$ per year

Fluxes in $\mathrm{Tg} \mathrm{N}$ per year

Fluxes in Sv

*Only advective flux is considered

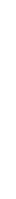

Fig. 1 | One-box model of the pycnocline for estimating water and nutrient transports and the model's results. Based on observations, the model solves for the steady-state conditions in the pycnocline. a, Schematic of the meridional overturning circulation showing the reservoirs and processes (Methods). Straight arrows represent water exchange terms, while curved arrows show export production and remineralization. $\mathbf{b}$, Nitrogen fluxes, including the gross inputs of nitrate to the pycnocline (that is, $\Omega+M_{\mathrm{in},}$ in $\mathrm{Tg} N$ per year) and export production and remineralization fluxes (in Tg $N$ per year) (mean \pm s.d.). c, Deconvolution of advective and mixing components, $\Omega$ and $M$ (mean \pm s.d.), derived from the model best fits and prior estimates of the advective flows ${ }^{38,39}(\omega$, in Sv and shown in blue). OAZ, Open Antarctic Zone; Low-lat. ML, low-latitude mixed layer.

long time periods, the net transport by mixing is down-gradient ${ }^{17}$. In our treatment of nutrients, the capital letters $\Omega$ and $M$ refer to the nutrient transport rates by the large-scale advective water transport, $\omega$, and by mixing, $m$, respectively. Gross nutrient transport by mixing is given by $M_{\text {in }}$ and $M_{\text {out }}$ for the transport into and out of the pycnocline, respectively. For example, $M_{\mathrm{S} \text {-in }}$ refers to the gross nutrient input to the pycnocline from the Southern Ocean. In contrast, large-scale advection only transports nutrients in the direction of the water flow. For example, $\Omega_{\mathrm{S}}$ refers to the advective nutrient input to the pycnocline from the Southern Ocean, whereas $\Omega_{\mathrm{N}}$ refers to the advective nutrient loss from the pycnocline to the high-latitude North Atlantic (Fig. 1).

Here, we use the nitrogen isotopic $\left({ }^{15} \mathrm{~N} /{ }^{14} \mathrm{~N}\right)$ ratio of nitrate $\left(\mathrm{NO}_{3}^{-}\right)$as a new tracer with which to reconstruct the sources of water and nutrients to the pycnocline. The sensitivity of this tracer for this application stems from the elevation in $\mathrm{NO}_{3}{ }^{-15} \mathrm{~N} /{ }^{14} \mathrm{~N}$ in Southern Ocean surface waters due to partial consumption of $\mathrm{NO}_{3}{ }^{-}$ by phytoplankton, which makes the Southern Ocean's contribution of $\mathrm{NO}_{3}^{-}$to the low-latitude pycnocline isotopically distinct from the $\mathrm{NO}_{3}{ }^{-}$entering from the underlying deep ocean. We calculate the mean pycnocline and extra-pycnocline values for the concentrations of oxygen $\left(\mathrm{O}_{2}\right)$, phosphate $\left(\mathrm{PO}_{4}{ }^{3-}\right)$ and $\mathrm{NO}_{3}{ }^{-}$and for the $\delta^{15} \mathrm{~N}$ of $\mathrm{NO}_{3}^{-}$(Fig. 2a and Table $1 ; \delta^{15} \mathrm{~N}=\left\{{ }^{15} \mathrm{~N} /{ }^{14} \mathrm{~N}\right\}_{\text {sample }} /\left\{{ }^{15} \mathrm{~N} /{ }^{14} \mathrm{~N}\right\}_{\text {reference }}-1$, with atmospheric $\mathrm{N}_{2}$ as reference). We develop a one-box model of the pycnocline under steady-state conditions (Fig. 1a). The model is constrained by the calculated mean pycnocline properties to estimate the relative importance of the Southern Ocean surface versus the deep ocean in the gross nutrient supply to the pycnocline (Fig. 1b). For this purpose, we define the term 'pycnocline recipe' as the proportion of nutrient in the pycnocline deriving from the Southern Ocean surface: $\left(\Omega_{\mathrm{S}}+M_{\mathrm{S} \text {-in }}\right) /\left(\Omega_{\mathrm{S}}+M_{\mathrm{S} \text {-in }}+\Omega_{\mathrm{D}}+M_{\mathrm{D} \text {-in }}\right)$. We also consider an advection-only, water-specific analogue, which we term the 'overturning ratio': $\omega_{\mathrm{S}} /\left(\omega_{\mathrm{S}}+\omega_{\mathrm{D}}\right)$. When combined with other information, the model also provides novel information on the respective roles of the large-scale advective transport $(\omega)$ and mixing $(m)$ in nutrient transport (Fig. 1c).

\section{Nitrate ${ }^{15} \mathrm{~N} /{ }^{14} \mathrm{~N}$ as a tracer of nutrient fluxes}

Southern Ocean processes cause $\mathrm{NO}_{3}{ }^{-} \delta^{15} \mathrm{~N}$ in the ocean's pycnocline to be higher than that in the deep ocean ${ }^{18-20}$. Partial $\mathrm{NO}_{3}{ }^{-}$assimilation in the Southern Ocean raises the $\delta^{15} \mathrm{~N}$ of $\mathrm{NO}_{3}{ }^{-}$in surface waters because of the preferential extraction of ${ }^{14} \mathrm{~N}$ for incorporation into new biomass ${ }^{21}$. In the PFZ and SAZ, surface waters enter the ocean interior as AAIW and SAMW, spreading the elevated $\delta^{15} \mathrm{~N}$ signal northward into the global pycnocline while lowering the $\mathrm{NO}_{3}{ }^{-} \delta^{15} \mathrm{~N}$ of the deep ocean through the regeneration of the low- $\delta{ }^{15} \mathrm{~N}$ sinking organic matter produced in the Southern Ocean surface ${ }^{19,20}$ (Fig. 2d). In the low- and mid-latitude ocean, the $\mathrm{NO}_{3}{ }^{-}$supply to the surface mixed layer is nearly completely consumed by phytoplankton assimilation, such that sinking nitrogen $\delta^{15} \mathrm{~N}$ is similar to that of the $\mathrm{NO}_{3}{ }^{-}$supply to the mixed layer ${ }^{22,23}$. Since nitrification in the ocean interior typically competes with no other process, the $\delta^{15} \mathrm{~N}$ of the $\mathrm{NO}_{3}{ }^{-}$added to the ocean interior by remineralization is largely determined by the $\delta^{15} \mathrm{~N}$ of the sinking $\mathrm{N}$ from the surface 
a
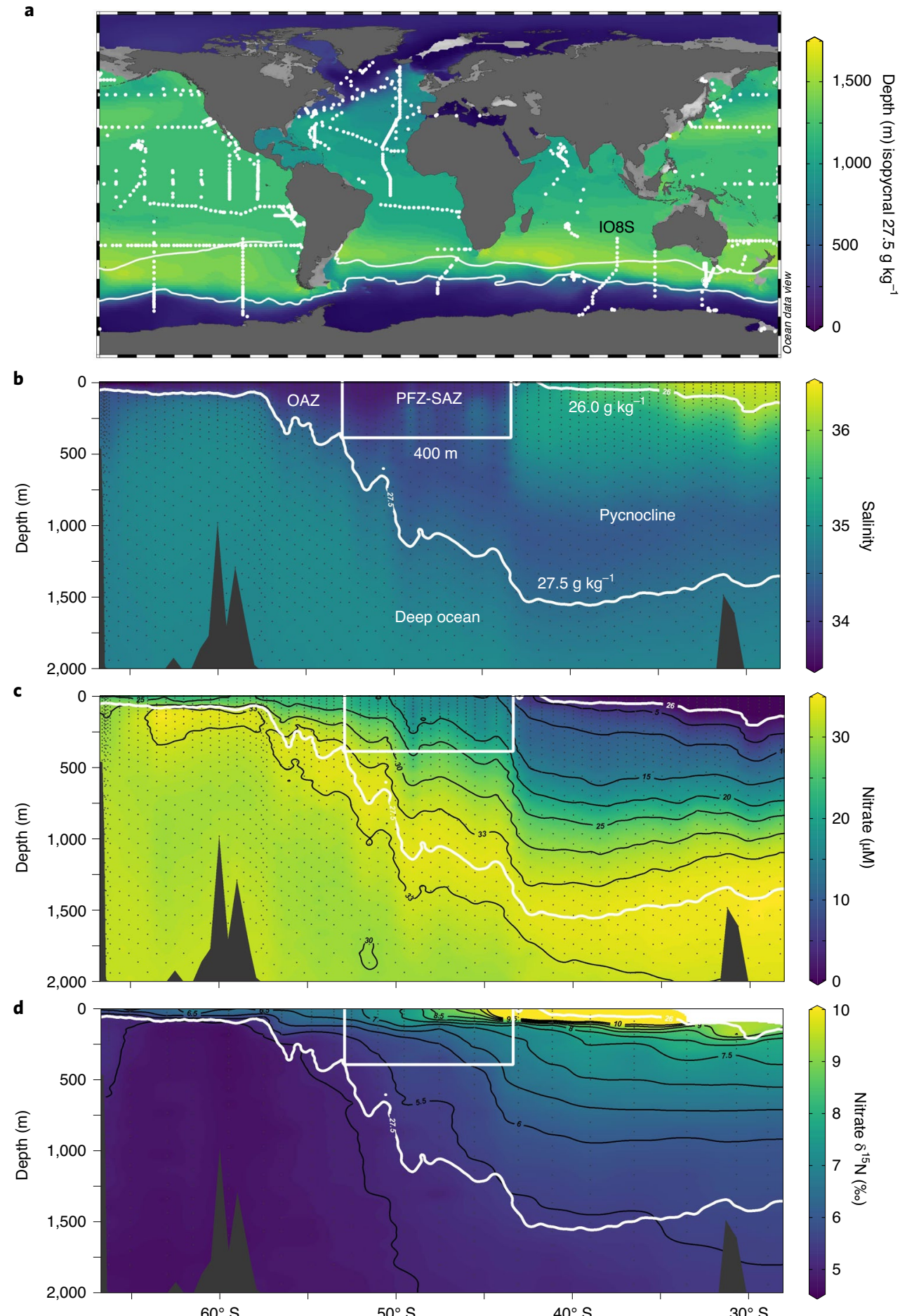

Fig. 2 | Nitrate isotopes and the Southern Ocean's imprint on the pycnocline. $\mathbf{a}$, Location of $\mathrm{NO}_{3}{ }^{-}$isotope data on the depth of the $27.5 \mathrm{~g} \mathrm{~kg}{ }^{-1}$ isopycnal. b-d, Depth sections of salinity (b), $\mathrm{NO}_{3}{ }^{-}$concentration (c) and $\delta^{15} \mathrm{~N}$ (d) in the Indian Sector (IO8S GOSHIP section). The 26.0 and $27.5 \mathrm{~g}$ kg ${ }^{-1}$ isopycnals are shown with white lines. The white rectangle outlines the average winter mixed layer in the PFZ-SAZ ${ }^{46}$.

ocean $^{20,24}$. The internal cycling of $\mathrm{N}$ in the low- and mid-latitude ocean therefore preserves the high- $\delta^{15} \mathrm{~N}$ imprint of the Southern Ocean on pycnocline $\mathrm{NO}_{3}{ }^{-}$(refs. ${ }^{19,20,24}$ ).

Our model corroborates a positive relationship between the pycnocline recipe and the mean difference in $\mathrm{NO}_{3}{ }^{-} \delta^{15} \mathrm{~N}$ between the pycnocline and the deep ocean (Fig. 3a). That is, the $\delta^{15} \mathrm{~N}$ difference increases as the relative contribution of SAMW + AAIW to the pycnocline nutrient budget increases. The upper bound produced by the model is indistinguishable from the conservative mixing line between the two end-members of the PFZ-SAZ source and the deep ocean source (Table 1 and black line in Fig. 3a).

The export of low- $\delta^{15} \mathrm{~N}$ organic $\mathrm{N}$ from the PFZ-SAZ and its associated remineralization in the pycnocline counteract the increase in pycnocline $\mathrm{NO}_{3}{ }^{-} \delta^{15} \mathrm{~N}$ from the subduction of ${ }^{15} \mathrm{~N}$-enriched $\mathrm{NO}_{3}^{-}$. Increasing the fraction of the exported organic $\mathrm{N}$ from the PFZ-SAZ that is remineralized within the pycnocline decreases the 
Table 1 | Weighted properties of each domain for dissolved oxygen $\left(\mathrm{O}_{2}\right)$, phosphate $\left(\mathrm{PO}_{4}{ }^{3-}\right)$ and nitrate $\left(\mathrm{NO}_{3}{ }^{-}\right)$ concentrations (World Ocean Atlas 2013), and $\mathrm{NO}_{3}{ }^{-} \delta^{15} \mathrm{~N}$ (this study)

\begin{tabular}{|c|c|c|c|c|c|}
\hline & \multirow{2}{*}{$\frac{\mathrm{O}_{2}}{\mu \mathrm{mol} \mathrm{\textrm {I } ^ { - 1 }}}$} & \multirow{2}{*}{$\begin{array}{l}\mathrm{PO}_{4}{ }^{3-} \\
\mu \mathrm{mol} \mathrm{I-1}\end{array}$} & \multicolumn{2}{|c|}{$\mathrm{NO}_{3}^{-\mathrm{a}}$} & \multirow{2}{*}{$\frac{\mathrm{NO}_{3}{ }^{-} \boldsymbol{\delta}^{15} \mathrm{~N}}{\% \text { versus air }}$} \\
\hline & & & & $\mathrm{Oll}^{-1}$ & \\
\hline Pycnocline & 141.3 & 2.1 & 29.7 & 29.4 & 6.25 \\
\hline Deep ocean & 174.6 & 2.3 & 33.0 & 33.5 & 5.16 \\
\hline PFZ-SAZ & 273.4 & 1.4 & 18.9 & 18.9 & 7.00 \\
\hline Low-lat. ML & $226.0^{b}$ & $0^{b}$ & $0^{b}$ & & \\
\hline
\end{tabular}

${ }^{a}$ Values on the left from WOA13-Annual; Values on the right from the nitrate isotope compilation ${ }^{b}$ Fixed values: $\mathrm{O}_{2}$ saturation in low-lat. $\mathrm{ML}$, complete nutrient consumption in low-lat. $\mathrm{ML}$

$\delta^{15} \mathrm{~N}$ difference between the pycnocline and the deep ocean and the pycnocline relative to the conservative mixing line (Fig. 3a). Given the relatively small contribution of the PFZ-SAZ to total remineralization in the global pycnocline (for example, $<10 \%$ in the model best fits), this effect is limited.

Sources and sinks of fixed $\mathrm{N}$ also affect the mean pycnocline $\mathrm{NO}_{3}{ }^{-} \delta^{15} \mathrm{~N}\left(\right.$ ref. ${ }^{25}$ ). Being the main source of fixed $\mathrm{N}, \mathrm{N}_{2}$ fixation (and the subsequent nitrification of the newly fixed N) is largely responsible for introducing new $\mathrm{NO}_{3}{ }^{-}$to the ocean, with a $\delta^{15} \mathrm{~N}$ of approximately $-2 \%$ o to $0 \%$ (refs. ${ }^{26,27}$ ). Denitrification and related anaerobic pathways (for example, anaerobic ammonium oxidation) are the dominant mechanisms of oceanic fixed $\mathrm{N}$ loss. Denitrification in the water column preferentially removes low $-\delta^{15} \mathrm{~N} \mathrm{NO}_{3}{ }^{-}$and is thus instrumental in raising the $\delta^{15} \mathrm{~N}$ of ocean $\mathrm{NO}_{3}{ }^{-}$above that of $\mathrm{N}_{2}$ fixation $^{25,28,29}$. The isotopic discrimination associated with $\mathrm{N}$ loss in sediment porewaters is typically much weaker than for water-column $\mathrm{N}$ loss ${ }^{30,31}$. In an oceanic fixed $\mathrm{N}$ budget that is balanced for $\mathrm{N}$ and its isotopes, the $\delta^{15} \mathrm{~N}$ of the fixed $\mathrm{N}$ loss equals the $\delta^{15} \mathrm{~N}$ of the fixed $\mathrm{N}$ input ${ }^{25,28}$. Ocean $\mathrm{NO}_{3}^{-} \delta^{15} \mathrm{~N}$ will reflect this budget, hereafter referred to as the 'budget-driven' $\mathrm{NO}_{3}{ }^{-} \delta^{15} \mathrm{~N}$.

To consider the effects of the fixed $\mathrm{N}$ budget on the $\delta^{15} \mathrm{~N}$ difference between the pycnocline and the deep ocean, we develop a prognostic, time-dependent analogue of our inverse model. To capture the relevant pycnocline dynamics, it consists of an ocean subdivided into five boxes, and it allows a balance to be reached between $\mathrm{N}_{2}$ fixation and denitrification (Supplementary Information and Extended Data Fig. 1).

We first consider the model scenario where $\mathrm{N}_{2}$ fixation and denitrification are entirely restricted to the base of the pycnocline and above. This is likely an accurate representation of the real ocean: (i) $\mathrm{N}_{2}$ fixation occurs mostly in the low-latitude mixed layer ${ }^{32,33}$ and introduces newly fixed $\mathrm{NO}_{3}^{-}$to the pycnocline largely through low-latitude export production and its remineralization within the pycnocline ${ }^{34}$; (ii) most water column denitrification occurs in the oxygen-deficient zones, which are also located within the pycnocline $^{35}$; and (iii) the bulk of benthic denitrification occurs on the seafloor at depths that fall within the pycnocline or the overlying surface mixed layer ${ }^{35}$. In this scenario and independent of the model parameters, the $\mathrm{N}_{2}$ fixation-denitrification balance forces the pycnocline $\mathrm{NO}_{3}{ }^{-} \delta^{15} \mathrm{~N}$ towards the budget-driven $\mathrm{NO}_{3}{ }^{-} \delta^{15} \mathrm{~N}$. However, the difference in $\mathrm{NO}_{3}{ }^{-} \delta^{15} \mathrm{~N}$ between the pycnocline and the deep ocean is indistinguishable from a model scenario without $\mathrm{N}_{2}$ fixation and denitrification (Extended Data Fig. 2). Partial assimilation in the Southern Ocean followed by the sinking of organic $\mathrm{N}$ into the deep Southern Ocean and the subduction of AAIW + SAMW into the pycnocline lowers the $\mathrm{NO}_{3}{ }^{-} \delta^{15} \mathrm{~N}$ of the deep ocean relative to the pycnocline. This pycnocline-deep ocean $\mathrm{NO}_{3}{ }^{-} \delta^{15} \mathrm{~N}$ difference is proportional to the pycnocline recipe, regardless of whether $\mathrm{N}_{2}$ fixation and denitrification are included in the model.

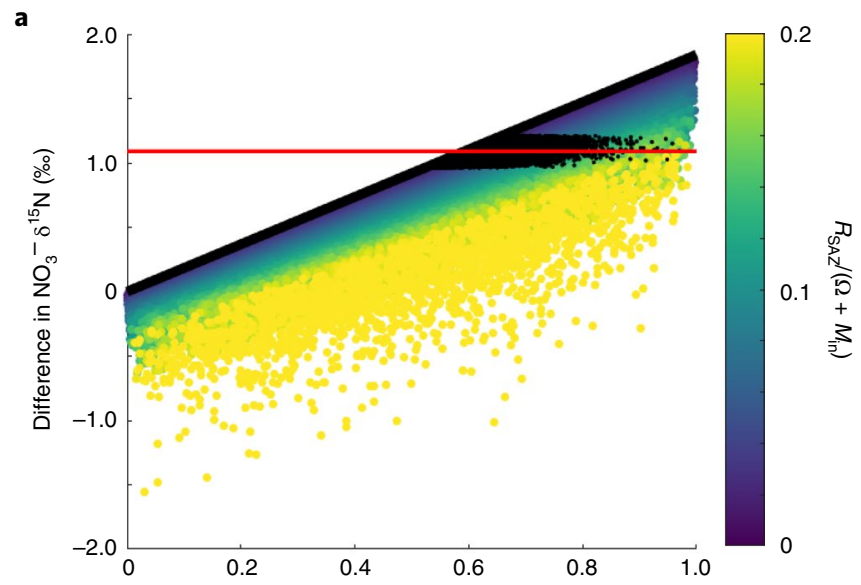

b

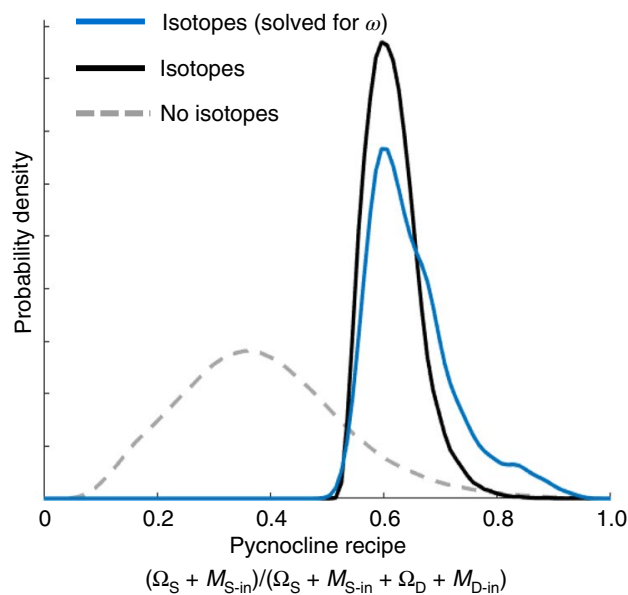

Fig. 3 | Model estimates of the fraction of nutrients transported into the pycnocline from the Southern Ocean surface versus the deep ocean.

a, Pycnocline recipe versus difference in $\mathrm{NO}_{3}{ }^{-} \delta^{15} \mathrm{~N}$ between the pycnocline and deep ocean calculated in the model solutions. The pycnocline recipe, $\left(\Omega_{\mathrm{S}}+M_{\mathrm{S} \text {-in }}\right) /\left(\Omega_{\mathrm{S}}+M_{\mathrm{s} \text {-in }}+\Omega_{\mathrm{D}}+M_{\mathrm{D} \text {-in }}\right)$, is the relative importance of the Southern Ocean surface versus the deep ocean in the gross nutrient (nitrate) supply to the pycnocline. The red line is the observed weighted average, while the black line is the conservative mixing line between the PFZ-SAZ ventilating region and the deep ocean (Table 1). Colour indicates the pycnocline PFZ-SAZ remineralization/gross nutrient transport ratio (in the currency of $N$ ) into the pycnocline (that is, $R_{\mathrm{SAZ}} /\left\{\Omega+M_{\text {in }}\right\}$ ). Black dots are model best fits. $\mathbf{b}$, Density function of the model best fits for the pycnocline recipe. The black line is with the constraints given by $\mathrm{NO}_{3}^{-}$ isotopes, the dashed grey line is without the constraints given by $\mathrm{NO}_{3}{ }^{-}$ isotopes, and the blue line is with the constraints given by $\mathrm{NO}_{3}^{-}$ isotopes and the additional constraints given by prior estimates of the advective flows ${ }^{38,39}$.

However, fixed $\mathrm{N}$ inputs and losses may not be entirely restricted to the base of the pycnocline and above. In particular, a fraction of benthic denitrification is likely to occur outside the pycnocline, either at high latitudes or below the depth of the pycnocline ${ }^{35}$. In the prognostic model, we explore the sensitivity of the pycnoclinedeep ocean $\mathrm{NO}_{3}{ }^{-} \delta^{15} \mathrm{~N}$ difference to the inclusion of some benthic denitrification occurring outside the pycnocline (Supplementary Information). This scenario increases the mean difference in $\mathrm{NO}_{3}{ }^{-}$ $\delta^{15} \mathrm{~N}$ between the pycnocline and the deep ocean by $0.10 \pm 0.05 \%$ o (mean \pm s.d.) in comparison with the model scenario without $\mathrm{N}_{2}$ fixation and denitrification (Extended Data Fig. 2). This is a small effect, within the uncertainties assumed in the data fitting activity 

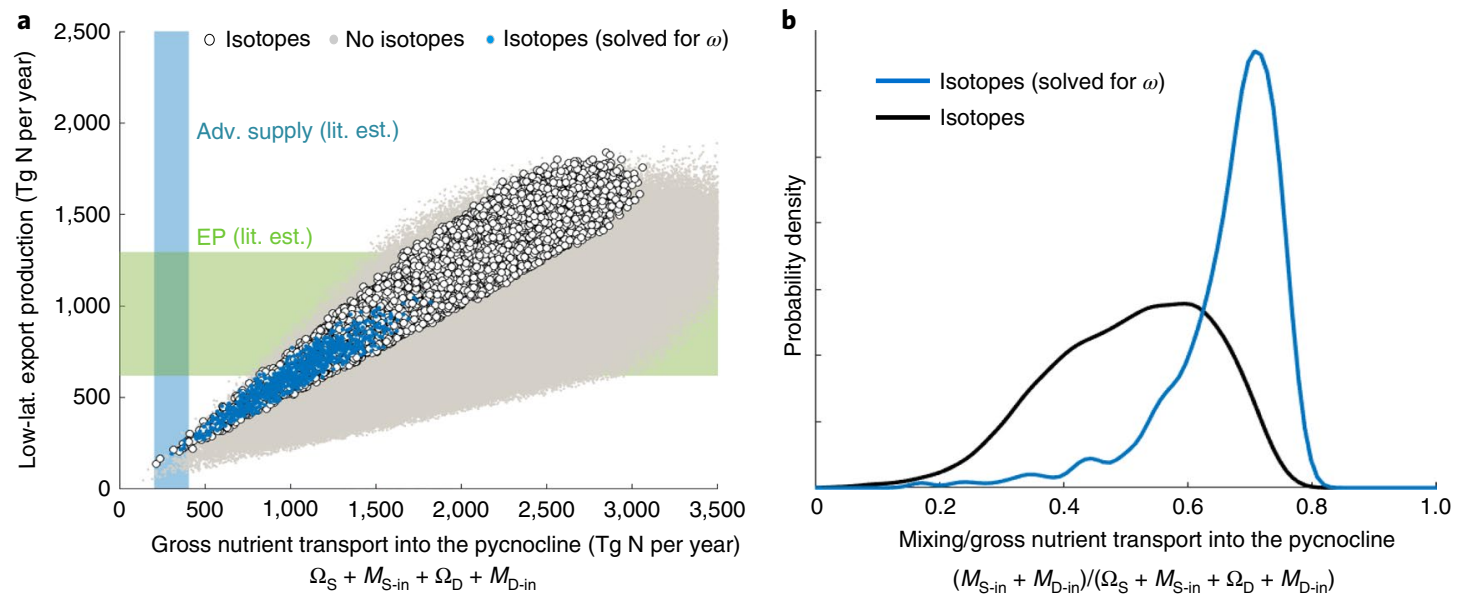

Fig. 4 | Use of observations of export production to partition the gross transport of nutrients between advective $(\Omega)$ and mixing $\left(M_{\text {in }}\right)$ nutrient supply. a, Gross nutrient transport into the pycnocline ( $\mathrm{Tg} N$ per year) versus low-latitude export production ( $\mathrm{Tg} N$ per year) for the model best fits (black circles). Grey symbols are without the constraint given by the $\mathrm{NO}_{3}{ }^{-}$isotopes. Blue circles are with the constraints given by the $\mathrm{NO}_{3}{ }^{-}$isotopes as well as the advective flows estimates taken from prior studies ${ }^{38,39}$. The range of estimates for the large-scale advective nutrient supply to the pycnocline $(\Omega$, in $\operatorname{Tg} \mathrm{N}$ per year) is shown with the blue bar ${ }^{38,39}$. The advective supply ('Adv. supply (lit. est.)') is a small fraction of the gross nutrient supply $\left(\Omega+M_{\text {in }}\right.$ ) required in most model solutions, including those consistent with literature estimates of export production ('EP (lit. est.)') $)^{41-44}$ (green bar). b, Density functions of the model best fits for the proportion of gross nutrient transport ratio into the pycnocline that is due to mixing (that is, $M_{\mathrm{in}} /\left\{\Omega+M_{\mathrm{in}}\right\}$ ). The black line is with the constraints given by $\mathrm{NO}_{3}{ }^{-}$isotopes, while the blue line is with the constraints given by $\mathrm{NO}_{3}{ }^{-}$isotopes and the additional constraints given by prior estimates of the advective flows ${ }^{38,39}$.

with the inverse, one-box model (Methods). In summary, while the ocean's fixed $\mathrm{N}$ input-output budget affects the $\mathrm{NO}_{3}{ }^{-} \delta^{15} \mathrm{~N}$ of both the pycnocline and the deep ocean, it has remarkably little effect on the pycnocline-deep ocean $\mathrm{NO}_{3}{ }^{-} \delta^{15} \mathrm{~N}$ difference.

\section{Nutrient sources to the pycnocline}

The central goal of this study is to exploit the sensitivities of $\mathrm{NO}_{3}{ }^{-}$ $\delta^{15} \mathrm{~N}$ to characterize the relative importance of the supply of water and nutrients to the low-latitude pycnocline from the Southern Ocean versus the underlying deep ocean. To do so, we solve the one-box model equations by varying the model parameters over a range well beyond literature estimates (Extended Data Table 1), targeting the best agreement between the observations and the model counterparts (Methods).

Temperature and salinity are not used as constraints in the standard version of the model inversion because these parameters (and temperature in particular) are characterized by intense lateral variation in the overlying surface mixed layer, such that correlated lateral variation in water fluxes could yield substantial systematic errors. This concern is validated by the observation that the model best fit predicts the most accurate pycnocline temperature when the temperature for the low-latitude mixed layer is taken from the higher-latitude margins of the low-latitude surface mixed layer (that is, the low-latitude regions poleward of $30^{\circ} \mathrm{N}$ and $30^{\circ} \mathrm{S}$; Supplementary Information). These regions are known for their ventilation of the pycnocline ${ }^{36,37}$. Regardless, including temperature and salinity constraints (using either the values of the bulk low-latitude mixed layer or those of the mixed layer poleward of $30^{\circ} \mathrm{N}$ and $30^{\circ} \mathrm{S}$ ) has an insignificant impact on the model best fit, with the pycnocline recipe being indistinguishable from the estimate produced without temperature and salinity constraints (Supplementary Information).

Despite the large range that is tested for the model parameters, the pycnocline recipe $\left(\left\{\Omega_{\mathrm{S}}+M_{\mathrm{S} \text {-in }}\right\} /\left\{\Omega_{\mathrm{S}}+M_{\mathrm{S} \text {-in }}+\Omega_{\mathrm{D}}+M_{\mathrm{D} \text {-in }}\right\}\right)$ is well constrained by the observations (Fig. 3b), with a median for the best fits of $0.61(0.56-0.68,10$ th to 90 th percentiles). This implies that $62 \pm 5 \%$ (mean \pm s.d.) of the $\mathrm{NO}_{3}^{-}$in the global pycnocline originates from the Southern Ocean. The same values are recovered if the pycnocline recipe is defined in terms of $\mathrm{PO}_{4}{ }^{3-}$ rather than $\mathrm{NO}_{3}{ }^{-}$. Our estimate for the pycnocline recipe is not significantly different if we allow that the mean difference in $\mathrm{NO}_{3}{ }^{-} \delta^{15} \mathrm{~N}$ between the pycnocline and the deep ocean is also impacted by a fraction of benthic denitrification occurring outside the pycnocline (Extended Data Fig. 2), which yields a median for the best fits of $0.59(0.53-0.66,10$ th to 90 th percentiles).

Our estimate for the pycnocline recipe is modestly lower than the estimate of $75 \%$ obtained using a nutrient-restoring approach coupled to an ocean general circulation model ${ }^{12}$. Our findings call for more equal contributions of nutrients from Southern Ocean surface and deep waters than the previous study but still indicate that the Southern Ocean supplies the greater part of the pycnocline nutrient reservoir. General circulation models parameterized with different physical terms (that is, subgrid-scale mixing terms) yield divergent pycnocline recipes, but these different models can nevertheless be tuned to produce similar physical and biogeochemical tracer fields ${ }^{2,3}$. Using a suite of such models, Palter et al. ${ }^{3}$ estimated a Southern Ocean contribution to the low-latitude pycnocline of $33-75 \%$ for $\mathrm{PO}_{4}{ }^{3-}$. Excluding the constraints imposed by the $\mathrm{NO}_{3}{ }^{-}$ isotope data, our calculations yield a similarly broad range for the pycnocline recipe (Fig. 3b), illustrating the benefit of including the $\mathrm{NO}_{3}{ }^{-}$isotopes as a model constraint.

The decomposition of the fluxes into their advective and mixing components is less constrained by the observations. Nevertheless, our estimates are consistent with the prevalent view of the Southern Ocean's wind-driven upwelling as greater than deep upwelling in the advective input of water to the pycnocline ${ }^{11-14}$, with a median overturning ratio of $0.75(0.56-0.94,10$ th to 90 th percentiles). In addition, a significant proportion of gross nutrient transport into the pycnocline is due to mixing (Fig. 4b), with a median $M_{\text {in }} /\left(\Omega+M_{\text {in }}\right)$ ratio of $0.52(0.33-0.67,10$ th to 90 th percentiles $)$.

\section{Importance of mixing for the exchange of nutrients}

To further decompose the nutrient transports from both the Southern Ocean and the deep ocean into their advective $(\Omega)$ and 
mixing $\left(M_{\mathrm{in}}\right)$ components, we make use of prior literature estimates $^{38,39}$ for large-scale advective fluxes $(\omega)$. By combining altimetric and gridded hydrographic data, Karsten and Marshall ${ }^{38}$ estimated a subduction rate (that is, residual overturning) from the PFZ-SAZ ventilating area $\left(\omega_{S}\right)$ of $30 \pm 5 \mathrm{~Sv}$. Based on the energy conversion from tidal and geostrophic motions into internal waves combined with a turbulent mixing parameterization, Nikurashin and Ferrari ${ }^{39}$ estimated an interior upwelling rate across the $27.5 \mathrm{~g} \mathrm{~kg}^{-1}$ isopycnal $\left(\omega_{\mathrm{D}}\right)$ of $3.5 \pm 0.8 \mathrm{~Sv}$. These estimates yield an overturning ratio of $0.90 \pm 0.20$, at the high end of the estimates given by our model best fits $(0.75 \pm 0.15)$.

The model best fits for which $\omega_{\mathrm{S}}$ and $\omega_{\mathrm{D}}$ are in the ranges of prior literature estimates ${ }^{38,39}$ yield a median (10th to 90th percentiles) for the pycnocline recipe of $0.63(0.57-0.75)$, indistinguishable from the pycnocline recipe estimated without these additional constraints (Fig. 3b). The nutrient supplies by advection $(\Omega)$ and mixing $\left(M_{\text {in }}\right)$ are well constrained by the observations (Fig. 1c), with a median $M_{\text {in }} /\left(\Omega+M_{\text {in }}\right)$ ratio of $0.69(0.55-0.75,10$ th to 90 th percentiles) (Fig. $4 \mathrm{~b}): 0.59(0.43-0.67)$ for the Southern Ocean and 0.86 $(0.69-0.92)$ for the deep ocean. The mixing components $\left(m_{\mathrm{D}}\right.$ and $\left.m_{\mathrm{S}}\right)$ correspond to diffusivity coefficients $\left(\kappa\right.$ in $\left.\mathrm{m}^{2} \mathrm{~s}^{-1}\right)$ that match prior literature estimates ${ }^{8,40}$ (Supplementary Information). The results imply that mixing contributes $\sim 70 \%$ of the gross nutrient supply to the pycnocline and therefore plays a substantial role in sustaining low-latitude biological productivity. As predicted, our model yields a positive linear relationship between the gross nutrient import to the pycnocline $\left(\Omega+M_{\text {in }}\right)$ and the export production in the low-latitude areas (Fig. 4a). With the additional constraints of the large-scale advective fluxes ${ }^{38,39}$, export production for the low-latitude areas is estimated to be $629 \pm 160 \mathrm{Tg} \mathrm{N}$ per year (mean \pm s.d.), in the lower range of previous estimates $\left(620-1290 \mathrm{Tg} \mathrm{N}\right.$ per year) ${ }^{41-44}$.

While both advection and mixing drive large gross nutrient fluxes into the pycnocline, mixing also carries nutrients out of the pycnocline $\left(M_{\text {out }}\right)$, both towards the Southern Ocean ventilation region and downwards into the deep ocean. In particular, net mixing-associated nutrient transport is from the pycnocline to the Southern Ocean, almost completely countering the advective nutrient input from the Southern Ocean (Fig. 1c). Thus, from the perspective of net fluxes, the deep ocean and the Southern Ocean contribute equally to the reservoir of nutrients in the pycnocline. One would not have inferred this situation from a purely advective view of ocean water fluxes.

At the same time, the mixing-associated nutrient effluxes from the pycnocline can be thought of as a consequence of the pycnocline's nutrient richness, which itself relies on the advective nutrient inputs. Advection drives the conversion of nutrient-rich water to predominantly nutrient-poor low-latitude surface waters that eventually flow to the North Atlantic: $82 \pm 15 \%$ of the advective outflow from the pycnocline passes through the low-latitude surface ocean (Fig. 1c). The essentially complete nutrient consumption in low-latitude surface waters requires that its nutrient supply is mostly returned to the pycnocline with export production and remineralization, effectively 'trapping' nutrients in the pycnocline. Over the last 30 years, the oceanographic community has come to appreciate the quantitative importance of eddies and their mixing in fuelling biological productivity ${ }^{45}$. While it is true that mixing dwarfs advection in the gross nutrient fluxes of the upper ocean, the advective circulation is ultimately responsible for the nutrient richness of the pycnocline.

\section{Online content}

Any methods, additional references, Nature Research reporting summaries, source data, extended data, supplementary information, acknowledgements, peer review information; details of author contributions and competing interests; and statements of data and code availability are available at https://doi.org/10.1038/ s41561-021-00836-8.
Received: 2 March 2021; Accepted: 7 September 2021; Published online: 1 November 2021

\section{References}

1. Frölicher, T. L. et al. Dominance of the Southern Ocean in anthropogenic carbon and heat uptake in CMIP5 models. J. Clim. 28, 862-885 (2015).

2. Gnanadesikan, A. et al. Oceanic ventilation and biogeochemical cycling: understanding the physical mechanisms that produce realistic distributions of tracers and productivity. Global Biogeochem. Cy. 18, GB4010 (2004).

3. Palter, J. B., Sarmiento, J. L., Gnanadesikan, A., Simeon, J. \& Slater, R. D. Fueling export production: nutrient return pathways from the deep ocean and their dependence on the Meridional Overturning Circulation. Biogeosciences 7, 3549-3568 (2010).

4. Stommel, H. \& Arons, A. B. On the abyssal circulation of the world ocean - II. An idealized model of the circulation pattern and amplitude in oceanic basins. Deep Sea Res. 6, 217-233 (1960).

5. Bryan, F. Parameter sensitivity of primitive equation ocean general circulation models. J. Phys. Oceanogr. 17, 970-985 (1987).

6. Munk, W. H. Abyssal recipes. Deep-Sea Res. 13, 707-730 (1966).

7. Ledwell, J. R., Watson, A. J. \& Law, C. S. Evidence for slow mixing across the pycnocline from an open-ocean tracer-release experiment. Nature 394, 701-703 (1993)

8. Groeskamp, S., Sloyan, B. M., Zika, J. D. \& McDougall, T. J. Mixing inferred from an ocean climatology and surface fluxes. J. Phys. Oceanogr. 47, 667-687 (2017)

9. Waterhouse, A. F. et al. Global patterns of diapycnal mixing from measurements of the turbulent dissipation rate. J. Phys. Oceanogr. 44, 1854-1872 (2014)

10. Toggweiler, J.R. \& Samuels, B. in The Global Carbon Cycle (ed. M. Heimann), NATO ASI series I, 15, 334-366 (Springer Verlag, 1993).

11. Toggweiler, J. R. \& Samuels, B. On the ocean's large-scale circulation near the limit of no vertical mixing. J. Phys. Oceanogr. 28, 1832-1852 (1998).

12. Sarmiento, J. L., Gruber, N., Brzezinski, M. A. \& Dunne, J. P. High-latitude controls of thermocline nutrients and low latitude biological productivity. Nature 427, 56-60 (2004).

13. Gnanadesikan, A., de Boer, A. M. \& Mignone, B. K. A simple theory of the pycnocline and overturning revisited.Geophys. Monogr. Ser. 173, 19-32 (2007).

14. Marshall, J. \& Speer, K. Closure of the meridional overturning circulation through Southern Ocean upwelling. Nat. Geosci. 5, 171-180 (2012).

15. Naveira-Garabato, A. C. et al. High-latitude ocean ventilation and its role in Earth's climate transitions. Phil. Trans. R. Soc. A 375, 20160324 (2017).

16. Yamamoto, A. et al. Roles of the ocean mesoscale in the horizontal supply of mass, heat, carbon, and nutrients to the Northern Hemisphere subtropical gyres. J. Geophys. Res. 123, 7016-7036 (2018).

17. Lee, M.-M. \& Williams, R. G. The role of eddies in the isopycnic transfer of nutrients and their impact on biological production. J. Mar. Syst. 58, 895-917 (2000).

18. Sigman, D. M., Altabet, M. A., McCorkle, D. C., Francois, R. \& Fischer, G. The $\delta^{15} \mathrm{~N}$ of nitrate in the Southern Ocean: consumption of nitrate in surface waters.Global Biogeochem. Cy. 13, 1149-1166 (1999).

19. Sigman, D. M. et al. The dual isotopes of deep nitrate as a constraint on the cycle and budget of oceanic fixed nitrogen. Deep Sea Res. I 56, 1419-1439 (2009).

20. Rafter, P. A., DiFiore, P. J. \& Sigman, D. M. Coupled nitrate nitrogen and oxygen isotopes and organic matter remineralization in the Southern and Pacific oceans. J. Geophys. Res. 118, 1-14 (2013).

21. Granger, J., Sigman, D. M., Needoba, J. A. \& Harrison, P. J. Coupled nitrogen and oxygen isotope fractionation of nitrate during assimilation by cultures of marine phytoplankton. Limnol. Oceangr. 49, 1763-1773 (2004).

22. Altabet, M. A. Variations in nitrogen isotopic composition between sinking and suspended particles: implications for nitrogen cycling and particle transformation in the open ocean. Deep Sea Res. 35, 535-553 (1988).

23. Altabet, M. A. \& Francois, R. Sedimentary nitrogen isotopic ratio as a recorder for surface ocean nitrate utilization. Global Biogeochem. Cy. 8, 103-116 (1994)

24. Marconi, D., Weigand, M. A. \& Sigman, D. M. Nitrate isotopic gradients in the North Atlantic Ocean and the nitrogen isotopic composition of sinking organic matter. Deep Sea Res. I 145, 109-124 (2019).

25. Brandes, J. A. \& Devol, A. H. A global marine-fixed nitrogen isotopic budget: implications for Holocene nitrogen cycling. Global Biogeochem. Cy. 16, 1120 (2002).

26. Minagawa, M. \& Wada, E. Nitrogen isotope ratios of red tide organisms in the East China Sea: a characterization of biological nitrogen fixation. Mar. Chem. 19, 245-259 (1986).

27. Carpenter, E. J., Harvey, H. R., Fry, B. \& Capone, D. G. Biogeochemical tracers of the marine cyanobacterium Trichodesmium. Deep Sea Res. 44, 27-38 (1997). 
28. Deutsch, C., Sigman, D. M., Thunell, R. C., Meckler, A. N. \& Haug, G. H. Isotopic constraints on glacial/interglacial changes in the oceanic nitrogen budget. Global Biogeochem. Cy. 18, GB4012 (2004).

29. Marconi, D., Kopf, S., Rafter, P. A. \& Sigman, D. M. Aerobic respiration along isopycnals leads to overestimation of the isotope effect of denitrification in the ocean water column. Geochim. Cosmochim. Acta 197, 417-432 (2017).

30. Lehmann, M. F. et al. The distribution of nitrate ${ }^{15} \mathrm{~N} /{ }^{14} \mathrm{~N}$ in marine sediments and the impact of benthic nitrogen loss on the isotopic composition of oceanic nitrate. Geochim. Cosmochim. 71, 5384-5404 (2007).

31. Brandes, J. A. \& Devol, A. H. Isotopic fractionation of oxygen and nitrogen in coastal marine sediments. Geochim. Cosmochim. Acta 61, 1793-1801 (1997).

32. Deutsch, C., Sarmiento, J. L., Sigman, D. M., Gruber, N. \& Dunne, J. P. Spatial coupling of nitrogen inputs and losses in the ocean. Nature 445, 163-167 (2007).

33. Wang, W.-L., Moore, J. K., Martiny, A. C. \& Primeau, F. W. Convergent estimates of marine nitrogen fixation. Nature 566, 205-210 (2019).

34. Gruber, N. \& Sarmiento, J. L. Global patterns of marine nitrogen fixation and denitrification. Global Biogeochem. Cy. 11, 235-266 (1997).

35. Bianchi, D., Dunne, J. P., Sarmiento, J. L. \& Galbraith, E. D. Data-based estimates of suboxia, denitrification, and $\mathrm{N}_{2} \mathrm{O}$ production in the ocean and their sensitivities to dissolved $\mathrm{O}_{2}$. Global Biogeochem. Cy. 26, GB2009 (2012).

36. McCartney, M. S. \& Talley, L. D. The subpolar mode water of the North Atlantic Ocean. J. Phys. Oceanogr. 12, 1169-1188 (1982).

37. Sarmiento, J. L. A tritium box model of the North Atlantic Thermocline. J. Phys. Oceanogr. 13, 1269-1274 (1983).

38. Karsten, R. H. \& Marshall, J. Constructing the residual circulation of the ACC from observations. J. Phys. Oceanogr. 32, 3315-3327 (2002).

39. Nikuarshin, M. \& Ferrari, R. Overturning circulation driven by breaking internal waves in the deep ocean. Geophys. Res. Lett. 40, 3133-3137 (2013).

40. Groeskamp, S., Laccases, J.H., McDougall, T.J \& Rogé, M., Full-depth global estimates of ocean mesoscale eddy mixing from observations and theory. Geophys. Res. Lett. https://doi.org/10.1029/2020GL089425 (2020).
41. Dunne, J. P., Sarmiento, J. L. \& Gnanadesikan, A. A synthesis of global particle export from the surface and cycling through the ocean interior and on the seafloor. Global Biogeochem. Cy. 21, GB4006 (2007).

42. Lutz, M. J., Caldeira, K., Dunbar, R. B. \& Behrenfeld, M. J. Seasonal rhythms of net primary production and particulate organic carbon flux to depth describe the efficiency of the biological pump in the global ocean. J. Geophys. Res. 112, C10011 (2007)

43. Henson, S. A. et al. A reduced estimate of the strength of the ocean's biological carbon pump. Geophys. Res. Lett. 38, L04606 (2011).

44. Laws, E. A., D'Sa, E. \& Naik, P. Simple equations to estimate ratios of new or export production to total production from satellite-derived estimates of sea surface temperature and primary production. Limnol. Oceanogr. Methods $\mathbf{9}$, 563-601 (2011)

45. Oschlies, A. Eddies and upper-ocean nutrient supply. Geophys. Monogr. Ser. 177, 115-130 (2008).

46. Dong, S., Sprintall, J., Gille, S. T. \& Talley, L. Southern Ocean mixed-layer depth from Argo float profiles. J. Geophys. Res. 113, C06013 (2008).

Publisher's note Springer Nature remains neutral with regard to jurisdictional claims in published maps and institutional affiliations. Attribution 4.0 International License, which permits use, sharing, adaptation, distribution and reproduction in any medium or format, as long
as you give appropriate credit to the original author(s) and the source, provide a link to the Creative Commons license, and indicate if changes were made. The images or other third party material in this article are included in the article's Creative Commons license, unless indicated otherwise in a credit line to the material. If material is not included in the article's Creative Commons license and your intended use is not permitted by statutory regulation or exceeds the permitted use, you will need to obtain permission directly from the copyright holder. To view a copy of this license, visit http://creativecommons. org/licenses/by/4.0/.

(c) The Author(s) 2021 


\section{Methods}

Data. New and previously published $\mathrm{NO}_{3}{ }^{-} \delta^{15} \mathrm{~N}$ measurements are reported. New hydrographic sections ( $n=147$ hydrocasts) are GOSHIP I08S (February 2016) in the eastern Indian sector, P18S (January 2017) in the eastern Pacific sector, GOSHIP P02 (March to June 2013) in the subtropical north Pacific, and GOSHIP P06 (November 2009 to February 2010) in the subtropical south Pacific for which the methodology has already been described ${ }^{47}$. These new datasets are compiled in combination with a database of $\mathrm{NO}_{3}{ }^{-} \delta^{15} \mathrm{~N}$ in the ocean, which includes most of the measurements published to date (Fig. 2a; see Supplementary Material for a description of the database and references). All data are available in the PANGAEA database $^{48}$, except the GOSHIP P02 and P06 sections, for which we report average profiles versus depth.

We compare the observations with the output of a one-box isotope model representing the pycnocline (Fig. 1a). We delineate the lower boundary of the pycnocline with the $27.5 \mathrm{~g} \mathrm{~kg}^{-1}$ isopycnal, located at $\sim 1,000-1,500 \mathrm{~m}$ depth in the low-latitude ocean and outcropping near the Antarctic Polar Front (APF) in the Southern Ocean and near the Subarctic Front in the North Atlantic (Fig. 2a). This boundary corresponds to the base of AAIW, which is well represented by the mid-depth salinity minimum spreading northwards in the different oceanic basins (Fig. 2b). In the North Pacific and Indian basins, this isopycnal does not outcrop to the north and remains relatively deep ( 1,000 m depth, Fig. $2 \mathrm{a})$. The northern limit in these basins is either the continental boundaries or the continental shelves (for example, the Bering Shelf). Between the APF and the Subtropical Front (STF), the upper pycnocline boundary is the base of the winter mixed layer $(\sim 400 \mathrm{~m} \mathrm{depth})^{46}$ Above this boundary and up to the surface is the region we define as the combined PFZ and SAZ ventilating area, where AAIW and SAMW are subducted into the pycnocline at the Antarctic Convergence. North of the STF, the upper pycnocline boundary is the depth of the $26.0 \mathrm{~g} \mathrm{~kg}^{-1}$ isopycnal. Above this boundary and up to the surface is defined here as the low-latitude mixed layer, which exchanges gases directly with the atmosphere and in which nutrients (including $\mathrm{NO}_{3}{ }^{-}$) are nearly completely consumed (Fig. 2c). The deep ocean is the region below the $27.5 \mathrm{~g} \mathrm{~kg}^{-1}$ isopycnal down to the seafloor, and between the southern and northern limits of the pycnocline defined above.

We used the World Ocean database 2013 (WOA13; annual properties with a resolution of $\left.1^{\circ}\right)^{49,50}$ to compute the weighted averages for $\mathrm{O}_{2}, \mathrm{PO}_{4}{ }^{3-}$ and $\mathrm{NO}_{3}$ concentrations for each domain according to the definitions outlined above. We first estimated the integrated properties at the scale of each domain (for example, moles of $\mathrm{NO}_{3}{ }^{-}$in the pycnocline) and then divided the integrated properties by the volume of the corresponding domain (Table 1). For the low-latitude mixed layer, we set the $\mathrm{NO}_{3}{ }^{-}$and $\mathrm{PO}_{4}{ }^{3-}$ concentrations to $\sim 0.0 \mu \mathrm{mol} \mathrm{L}^{-1}$ and the $\mathrm{O}_{2}$ concentration at saturation with the atmosphere, using the solubility as described in ref. ${ }^{51}$. For $\mathrm{NO}_{3}{ }^{-} \delta^{15} \mathrm{~N}$, the $\mathrm{NO}_{3}{ }^{-}$isotope database was used (Fig. 2a). The weighted averages were first computed for each station by taking the depth-integrated values divided by the representative thickness (see, for example, Extended Data Fig. 3 for the pycnocline). Given the relatively small amount of available data, there are inevitable biases in the dataset in terms of spatial coverage. For the PFZ-SAZ ventilating area and deep ocean, the median of the station's weighted averages is assumed to be representative of the mean properties of each domain. This approach appears to be robust because similar $\mathrm{NO}_{3}{ }^{-}$concentrations are reported for WOA13 (that is, annual properties) and the $\mathrm{NO}_{3}{ }^{-}$isotope database (Table 1). For the pycnocline, significant isotopic gradients are observed (Extended Data Fig. 3; see Supplementary Information for a discussion of the large-scale distribution of nitrate isotopes in the pycnocline), which could induce a sampling bias in the assessment of the mean pycnocline properties. These gradients are mostly driven by variable $\mathrm{NO}_{3}{ }^{-}$isotope budget-related fluxes and are restricted to the areas influenced by the North Atlantic Ocean and the Oxygen Minimum Zones ${ }^{19}$ (OMZs, contributing to $24 \%$ of the pycnocline $\mathrm{NO}_{3}{ }^{-}$pool). Relatively constant nitrate $\delta^{15} \mathrm{~N}$ is observed outside these areas (contributing to $76 \%$ of the pycnocline $\mathrm{NO}_{3}{ }^{-}$pool and with isotopic gradients of $<0.2 \%$ o for $\delta^{15} \mathrm{~N}$ between oceanic basins). We thus sorted the stations into three different categories, reflecting these variable isotope budgets: OMZ-influenced stations, North Atlantic-influenced stations and remaining pycnocline stations (Extended Data Fig. 3). The median properties were computed for each category and then weighted by the volume contribution of each category to the total pycnocline volume. The contributions of the North Atlantic Ocean and OMZ-influenced areas to the $\mathrm{NO}_{3}$ pool in the pycnocline are relatively small and, taken together, increase the mean pycnocline $\mathrm{NO}_{3}{ }^{-} \delta^{15} \mathrm{~N}$ by $0.2 \%$. In addition, the computed $\mathrm{NO}_{3}{ }^{-}$concentration for the pycnocline is indistinguishable from the weighted average estimated from the WOA13 (Table 1), giving us confidence in our approach.

One-box model. Nutrients and dissolved $\mathrm{O}_{2}$ are supplied into the pycnocline from the PFZ-SAZ ventilating area and the deep ocean (Fig. 1). This occurs by large-scale advective fluxes, that is, the subduction of AAIW and SAMW $\left(\omega_{\mathrm{S}}\right.$, the residual overturning circulation) and interior upwelling $\left(\omega_{\mathrm{D}}\right)$, and by mixing, that is, isopycnal mixing (eddy diffusion) between the PFZ-SAZ ventilating region and the pycnocline $\left(m_{\mathrm{S}}\right)$ and diapycnal mixing between the deep ocean and the pycnocline $\left(m_{\mathrm{D}}\right)$. The removal of nutrients and dissolved $\mathrm{O}_{2}$ occurs via a large-scale advective flux, that is, sinking $\left(\omega_{\mathrm{N}}=\omega_{\mathrm{S}}+\omega_{\mathrm{D}}\right)$ in the North Atlantic, which is partitioned between surface $\left(\omega_{\mathrm{N}-\mathrm{LL}}\right)$ and intermediate $\left(\omega_{\mathrm{N}-\mathrm{P}}\right)$ outflows, with $y$ denoting the $\omega_{\mathrm{N}-\mathrm{LL}} / \omega_{\mathrm{N}}$ ratio, and by mixing $\left(m_{\mathrm{S}}\right.$ and $\left.m_{\mathrm{D}}\right)$. In the model, $\omega_{\mathrm{N}-\mathrm{LL}}$ also includes the component of upwelling into the low-latitude surface that flows towards the PFZ-SAZ ventilating region ${ }^{38}\left(\mathrm{X}^{*}\right.$ in Fig. 1a). Mixing between the pycnocline and low-latitude mixed layer $\left(m_{\mathrm{LL}}\right)$ is also represented.

For nitrogen $(\mathrm{N})$, export production $(\phi)$ is controlled by the $\mathrm{NO}_{3}{ }^{-}$supply into the surface layer and the degree of $\mathrm{NO}_{3}{ }^{-}$consumption $\left(f_{\phi}\right)$. $\mathrm{NO}_{3}{ }^{-}$assimilation is assumed to proceed with an isotope effect of $5 \%$ for both the $\mathrm{N}$ and $\mathrm{O}$ isotopes ${ }^{17,20,47}$. A fraction $\left(f_{\mathrm{R}}\right)$ of the export production is regenerated in the pycnocline ( $R$; hereafter the subscripts 'LL' and 'SAZ' refer to low-latitude mixed layer and combined PFZ-SAZ ventilating region, respectively), including from $\phi_{\mathrm{SAZ}}$. The $\delta^{15} \mathrm{~N}$ of the $\mathrm{NO}_{3}{ }^{-}$added to the ocean interior by remineralization is largely determined by the $\delta^{15} \mathrm{~N}$ of the $\mathrm{N}$ exported from the surface ocean (that is, $\left.R \delta^{15} \mathrm{~N}=\phi \delta^{15} \mathrm{~N}\right)^{23}$. The same rationale is applied to $\mathrm{PO}_{4}{ }^{3-}$, using the same values for $\phi, f_{\phi}$ and $f_{\mathrm{R}}$ as for $\mathrm{NO}_{3}{ }^{-}$. In the pycnocline, the consumption of $\mathrm{O}_{2}$ during remineralization is based on $\mathrm{PO}_{4}{ }^{3-}$ and the $\mathrm{O}_{2} / \mathrm{PO}_{4}{ }^{3-}$ oxidation ratio of 140 associated with aerobic respiration ${ }^{52}$. Complete nutrient consumption in low-latitude surface waters (that is, $f_{\phi \text {-LL }}=1$ ) yields an N/P ratio for export production equivalent to the ratio of the nutrient supply (the pycnocline $\mathrm{N}: \mathrm{P}$ ratio of 14.1/1). This N/P ratio is lower than the average N/P ratio of marine phytoplankton (16/1) and than the still higher ratio of exported organic matter in the subtropical ocean ${ }^{53}$. The low N/P ratio calculated for low-latitude export production is a consequence of the absence of the fixed $\mathrm{N}$ budget in the one-box model. In the real ocean, fixed $\mathrm{N}$ inputs and losses are such that the $\mathrm{NO}_{3}{ }^{-} / \mathrm{PO}_{4}{ }^{3-}$ ratio of the global mean ocean (and the pycnocline) is less than $16 / 1$ (ref. ${ }^{34}$ ). In the PFZ-SAZ area, we define export production $\left(\phi_{\mathrm{SAZ}}\right)$ for $\mathrm{N}(0-250 \mathrm{Tg} \mathrm{N}$ per year), using an N:P ratio of 16/1 to determine export production for P. In the Supplementary Information, we test the sensitivity of the one-box model to variable N/P ratios. The outcome is not significantly different than in the standard run.

We solve the steady-state one-box model equations by varying the parameters over the sensitivity range given in Extended Data Table 1, for $\mathrm{O}_{2}$ concentration, $\mathrm{PO}_{4}{ }^{3-}$ concentration, $\mathrm{NO}_{3}{ }^{-}$concentration and $\mathrm{NO}_{3}{ }^{-} \delta^{15} \mathrm{~N}$, such that the inputs and outputs are balanced (that is, $\mathrm{d} x / \mathrm{d} t=0$ ):

$$
\begin{aligned}
V \frac{\mathrm{d} P}{\mathrm{~d} t}= & \omega_{\mathrm{S}} P_{\mathrm{SAZ}}+\omega_{\mathrm{D}} P_{\mathrm{D}}+m_{\mathrm{S}}\left(P_{\mathrm{SAZ}}-P\right) \\
& +m_{\mathrm{D}}\left(P_{\mathrm{D}}-P\right)+m_{\mathrm{LL}}\left(P_{\mathrm{LL}}-P\right)-\left(\omega_{\mathrm{N}-\mathrm{LL}}+\omega_{\mathrm{N}-\mathrm{P}}\right) P \\
& +f_{\mathrm{R}-\mathrm{SAZ}} \phi_{\mathrm{SAZ}}+f_{\phi-\mathrm{LL}} f_{\mathrm{R}-\mathrm{LL}}\left(m_{\mathrm{LL}}+\omega_{\mathrm{N}-\mathrm{LL}}\right) P \\
V \frac{\mathrm{d} N}{\mathrm{~d} t}= & \omega_{\mathrm{S}} N_{\mathrm{SAZ}}+\omega_{\mathrm{D}} N_{\mathrm{D}}+m_{\mathrm{S}}\left(N_{\mathrm{SAZ}}-N\right)+m_{\mathrm{D}}\left(N_{\mathrm{D}}-N\right) \\
& +m_{\mathrm{LL}}\left(N_{\mathrm{LL}}-N\right)-\left(\omega_{\mathrm{N}-\mathrm{LL}}+\omega_{\mathrm{N}-\mathrm{P}}\right) N+f_{\mathrm{R}-\mathrm{SAZ}} \phi_{\mathrm{SAZ}} \\
& +f_{\phi-\mathrm{LL}} f_{\mathrm{R}-\mathrm{LL}}\left(m_{\mathrm{LL}}+\omega_{\mathrm{N}-\mathrm{LL}}\right) N
\end{aligned}
$$

$$
\begin{aligned}
& V \frac{\mathrm{d} O}{\mathrm{~d} t}=\omega_{\mathrm{S}} O_{\mathrm{SAZ}}+\omega_{\mathrm{D}} O_{\mathrm{D}}+m_{\mathrm{S}}\left(O_{\mathrm{SAZ}}-O\right)+m_{\mathrm{D}}\left(O_{\mathrm{D}}-O\right)+m_{\mathrm{LL}}\left(O_{\mathrm{LL}}-O\right) \\
& -\left(\omega_{\mathrm{N}-\mathrm{LL}}+\omega_{\mathrm{N}-\mathrm{P}}\right) O-f_{\mathrm{R}-\mathrm{SAZ}} \phi_{\mathrm{SAZ}}\left(\frac{O}{P}\right)_{\mathrm{R}}-f_{\phi-\mathrm{LL}} f_{\mathrm{R}-\mathrm{LL}}\left(m_{\mathrm{LL}}+\omega_{\mathrm{N}-\mathrm{LL}}\right) P\left(\frac{O}{P}\right)_{\mathrm{R}}
\end{aligned}
$$

$$
\begin{aligned}
& V \frac{\mathrm{d}^{15} R}{\mathrm{~d} t}=\omega_{\mathrm{S}} N_{\mathrm{SAZ}}{ }^{15} R_{\mathrm{SAZ}}+\omega_{\mathrm{D}} N_{\mathrm{D}}{ }^{15} R_{\mathrm{D}}+m_{\mathrm{S}}\left(N_{\mathrm{SAZ}}{ }^{15} R_{\mathrm{SAZ}}-N^{15} R\right) \\
& +m_{\mathrm{D}}\left(N_{\mathrm{D}}{ }^{15} R_{\mathrm{D}}-N^{15} R\right)+m_{\mathrm{LL}}\left(N_{\mathrm{LL}}{ }^{15} R_{\mathrm{LL}}-N^{15} R\right)-\left(\omega_{\mathrm{N}-\mathrm{LL}}+\omega_{\mathrm{N}-\mathrm{P}}\right) N^{15} R \\
& +f_{\mathrm{R}-\mathrm{SAZ}} \phi_{\mathrm{SAZ}}{ }^{15} R_{\phi_{\mathrm{SAZ}}}+f_{\phi-\mathrm{LL}} f_{\mathrm{R}-\mathrm{LL}}\left(m_{\mathrm{LL}}+\omega_{\mathrm{N}-\mathrm{LL}}\right) N^{15} R\left(\frac{1-\left(1-f_{\phi-\mathrm{LL}}\right)^{1-\frac{{ }_{\varepsilon_{\text {ass }}}}{1,000}}}{f_{\phi} \text { - LL }}\right)
\end{aligned}
$$

$P$ is for $\mathrm{PO}_{4}{ }^{3-}\left(\mu \mathrm{mol} \mathrm{L}{ }^{-1}\right), N$ for $\mathrm{NO}_{3}{ }^{-}\left(\mu \mathrm{mol} \mathrm{L}{ }^{-1}\right), O$ for $\mathrm{O}_{2}\left(\mu \mathrm{mol} \mathrm{L}{ }^{-1}\right)$ and ${ }^{15} R$ for the ${ }^{15} \mathrm{~N} /{ }^{14} \mathrm{~N}$ ratio in $\mathrm{NO}_{3}{ }^{-}$. Most of the parameters are described in Extended Data Table 1, except the following: $V$ is the volume of the pycnocline $\left(2.8 \times 10^{20} \mathrm{~L}\right)$ and $(O / P)_{\mathrm{R}}$ is the respiratory quotient $(140)$ (ref. ${ }^{52}$ ).

Our assumption of a steady state for the pycnocline is justified by the residence time of its nutrients calculated from the model best fits with the additional constraints given by prior estimates of the advective flows ${ }^{38,39}$, that is, $121 \pm 40$ years. This residence time is beyond the observed timescale for variations in the ventilation of the pycnocline by the Southern Ocean over recent decades ${ }^{54}$, and the fluxes investigated here are unlikely to change dramatically within the Holocene, including the early stages of anthropogenic global warming. Thus, while the assumption of steady state deserves further investigation, it is justified for this first application of the $\mathrm{NO}_{3}{ }^{-}$isotopes to infer nutrient fluxes at the scale of the pycnocline.

Model optimization. To estimate the best fit with the observations, we solve the model equations by varying the parameters over the sensitivity ranges given in Extended Data Table 1, targeting the best agreement between the observations $\left\{\left[\mathrm{O}_{2}\right],\left[\mathrm{PO}_{4}{ }^{3-}\right],\left[\mathrm{NO}_{3}{ }^{-}\right], \mathrm{NO}_{3}{ }^{-} \delta^{15} \mathrm{~N}\right\}($ Table 1$)$ and the model counterparts $\left\{\left[\mathrm{O}_{2}\right]\right.$ 
$\left.\left[\mathrm{PO}_{4}^{3-}\right],\left[\mathrm{NO}_{3}{ }^{-}\right], \mathrm{NO}_{3}{ }^{-} \delta^{15} \mathrm{~N}\right\}$. For each model parameter, we generated $30 \times 10^{6}$ random numbers in the parameter sensitivity range (Extended Data Table 1), giving the same number of model scenarios. For each model scenario, we assess the discrepancy between observations and model counterparts, using the standardized residual (SR), as follows ${ }^{55}$.

$$
\mathrm{SR}_{i}=\left(\frac{X_{\mathrm{m}}-X_{i}}{\sigma_{i}}\right)
$$

with $X_{i}$ representing the observation, $X_{\mathrm{m}}$ the model counterpart and $\sigma_{i}$ the standard error for the corresponding observation. Normalizing the standard errors solves the problem of scaling between different model variables. In WOA13, the mean standard error is $0.5 \mu \mathrm{M}$ for $\mathrm{NO}_{3}^{-}$concentration, $0.05 \mu \mathrm{M}$ for $\mathrm{PO}_{4}^{3-}$ concentration and $3.4 \mu \mathrm{M}$ for $\mathrm{O}_{2}$ concentration ${ }^{49,50}$. In the $\mathrm{NO}_{3}{ }^{-}$isotope database, the standard errors on the mean weighted properties are $0.05 \%$ for $\mathrm{NO}_{3}{ }^{-} \delta^{15} \mathrm{~N}$.

The model best fits are then estimated using the residual sum of squares (RSS), as follows:

$$
\mathrm{RSS}=\sum_{i}^{n}\left(\mathrm{SR}_{i}\right)^{2}
$$

and correspond to the lowest RSS values, which represent the best agreement between observations and model counterparts. All model scenarios with an RSS value lower than 7 are considered a model best fit. The model best fits reproduce satisfactory $\mathrm{O}_{2}$ concentration, $\mathrm{PO}_{4}{ }^{3-}$ concentration, $\mathrm{NO}_{3}{ }^{-}$concentration and $\mathrm{NO}_{3}{ }^{-} \delta^{15} \mathrm{~N}$ : with SRs symmetrically distributed with a mean not significantly different from zero and within two standard errors of the observations (Extended Data Fig. 4a). Accordingly, there is no evidence of systematic errors in the model optimization scheme. We also tested an optimization scheme in which the model best fits are the model scenarios falling within two standard errors for each model variable (Extended Data Fig. 4b). No significant differences are reported between the two optimization schemes (see Extended Data Fig. 5 for the pycnocline recipe), which supports our RSS approach.

To assess the influence of the values selected for the standard errors, we run the optimization with different values for the standard errors, that is, two times lower and higher than the values reported in WOA13 and in the $\mathrm{NO}_{3}{ }^{-}$isotope database. Extended Data Fig. 6 shows the distribution of the model best fits for $\mathrm{O}_{2}$ concentration, $\mathrm{NO}_{3}^{-}$concentration and $\mathrm{NO}_{3}{ }^{-} \delta^{15} \mathrm{~N}$. Lower (higher) standard errors decrease (increase) the spread of the model best fits without significantly changing the mean values, including for the pycnocline recipe (Extended Data Fig. 5).

\section{Data availability}

The authors declare that the data supporting the findings of this study are available in the PANGAEA database. (https://doi.org/10.1594/PANGAEA.936484)

\section{Code availability}

The authors declare that the code supporting the findings of this study is available in Methods section.

\section{References}

47. Fripiat, F. et al. The isotope effect of nitrate assimilation in the Antarctic Zone: improved estimates and paleoceanographic implications. Geochim. Cosmochim. Acta 247, 261-279 (2019).

48. Fripiat et al. Compilation of Nitrate $\delta \mathrm{N}$ in the Ocean (PANGAEA, 2021); https://doi.org/10.1594/PANGAEA.936484
49. Garcia, H. E. et al. World Ocean Atlas 2013, Volume 3: Dissolved Oxygen, Apparent Oxygen Utilization, and Oxygen Saturation (ed. Levitus, S., technical ed. Mishonov, A.) NOAA Atlas NESDIS Vol. 75, 27 (NOAA, 2014).

50. Garcia, H.E., et al. World Ocean Atlas 2013, volume 4: Dissolved Inorganic Nutrients (Phosphate, Nitrate, Silicate) (ed. Levitus, S., technical ed. Mishonov, A.) NOAA Atlas NESDIS 76, 26pp (NOAA, 2014).

51. Weiss, R. F. The solubility of nitrogen, oxygen and argon in seawater. Deep Sea Res. 17, 721-735 (1970).

52. Anderson, L. A. On the hydrogen and oxygen content of marine phytoplankton. Deep Sea Res. 42, 1675-1680 (1995).

53. Weber, T. \& Deutsch, C. Oceanic nitrogen reservoir regulated by plankton diversity and ocean circulation. Nature 489, 419-422 (2012).

54. Waugh, D., Primeau, F., DeVries, T. \& Holzer, M. Recent changes in the ventilation of the Southern Oceans. Science 339, 568-570 (2013).

55. Elskens, M. et al. Statistical process control in assessing production and dissolution rates of biogenic silica in marine environments. Mar. Chem. 106, 272-286 (2007)

\section{Acknowledgements}

The authors thank the ship captains, crews and chief scientists (GOSHIP and GEOTRACES) who supported the sampling activities during the various field programs that contributed to this study, and S. Oleynik and M.A. Weigand (Princeton University), and B. Hinnenberg and F. Rubach (MPIC) for analytical advice and support and for help with sample processing. The data analysis and modeling components of this study, as well as a portion of the nitrate isotope measurements, were funded by the Max Planck Society. D.M.S. acknowledges US NSF grants OCE-0960802, 1851430, 1736652 and 2049416 . S.E.F. acknowledges the South African NRF and SANAP (through grants 129232, 110735 and 115335), and the support of a Royal Society/AAS FLAIR fellowship. P.A.R. acknowledges US NSF grants OCE-2015647 and OCE-2032340. SHK acknowledges US NSF grant OCE2041539 and the support of an Agouron Institute fellowship.

\section{Author contributions}

F.F., A.M.-G., D.M.S. and G.H.H. designed the study. F.F. wrote the first version of the manuscript, with feedback from D.M.S. F.F., D.M., S.E.F., S.H.K., V.H.L., P.A.R. and R.Z. performed most of the nitrate isotope analysis under the supervision of A.M.-G. and D.M.S. All authors contributed to the interpretation of the data and provided significant input to the final manuscript.

\section{Funding}

Open access funding provided by the Max Planck Society.

\section{Competing interests}

The authors declare no competing interests.

\section{Additional information}

Extended data is available for this paper at https://doi.org/10.1038/s41561-021-00836-8.

Supplementary information The online version contains supplementary material available at https://doi.org/10.1038/s41561-021-00836-8.

Correspondence and requests for materials should be addressed to François Fripiat.

Peer review information Nature Geoscience thanks Alberto Naveira Garabato, Sjoerd Groeskamp and the other, anonymous, reviewer(s) for their contribution to the peer review of this work. Primary Handling Editor(s): Xujia Jiang and Kyle Frischkorn.

Reprints and permissions information is available at www.nature.com/reprints. 


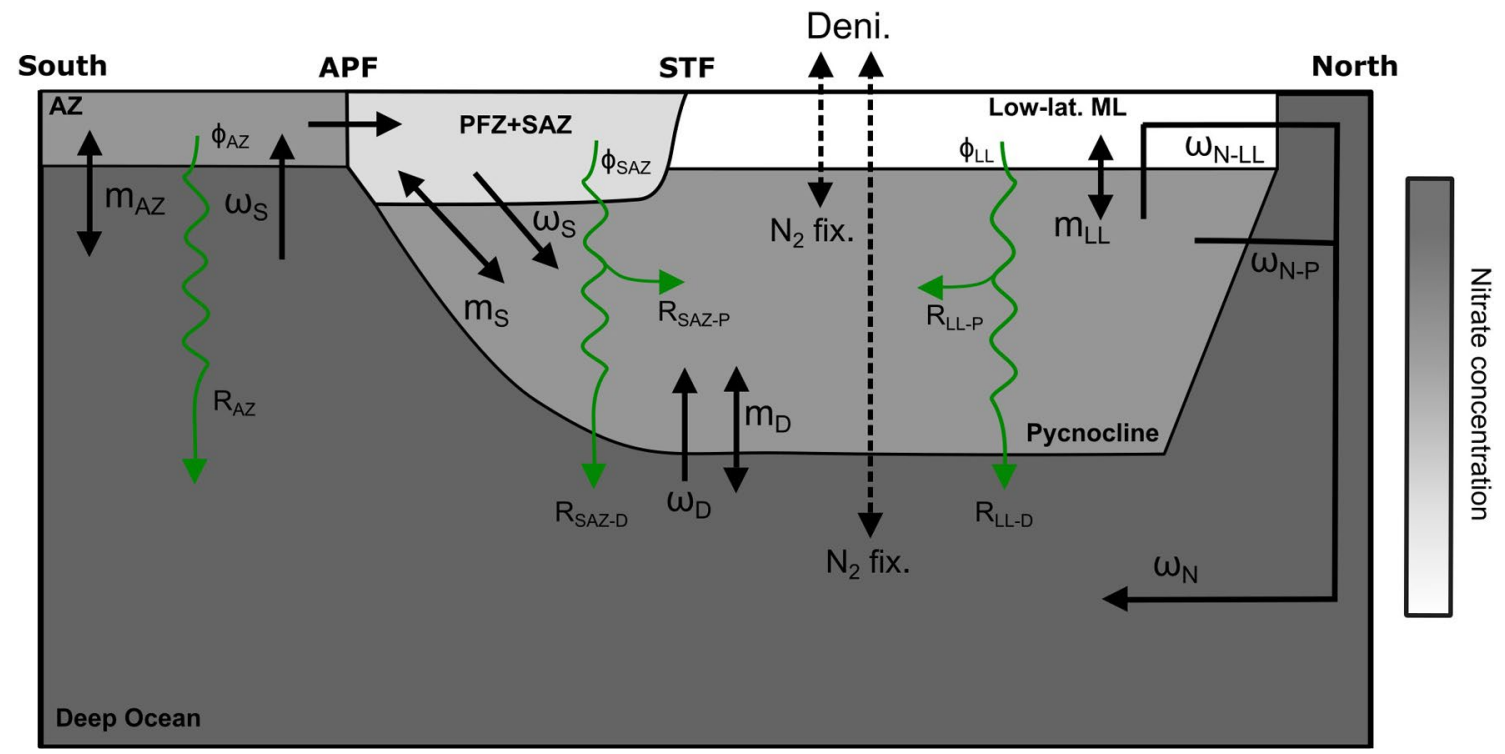

Extended Data Fig. 1| Prognostic five-box ocean model. Schematic of the meridional overturning circulation showing the reservoirs and processes included in the prognostic five-box ocean model (see Supplementary Material). This model is used to test the effects of the fixed $\mathrm{N}$ budget on the $\mathrm{NO}_{3}{ }^{-} \delta^{15} \mathrm{~N}$ difference between the deep ocean and the pycnocline. The symbols in the diagram follow those in the main text and Fig. 1. Straight arrows represent water exchange terms, curved arrows show export production and remineralization, and dashed arrows indicate the addition and removal of nitrate by $\mathrm{N}_{2}$ fixation ( $\mathrm{N}_{2}$ fix.) and denitrification (Deni.), respectively, occurring either in the pycnocline or in the deep ocean. The five boxes are the deep ocean, the pycnocline, the AZ mixed layer, the PFZ-SAZ ventilating area, and the low-latitude mixed layer. The values used for the model parameters are varied over the same sensitivity ranges as in the one-box model (Extended Data Table 1); except for $\mathrm{m}_{\mathrm{AZ}}$ and the degree of $\mathrm{NO}_{3}{ }^{-}$consumption in both the AZ mixed layer and PFZ-SAZ ventilating area, which are held constant (at $20 \mathrm{~Sv}, 0.12$ and 0.16 , respectively), and denitrification, which varies from 100 to $250 \operatorname{Tg~N~yr}{ }^{-1}$. 


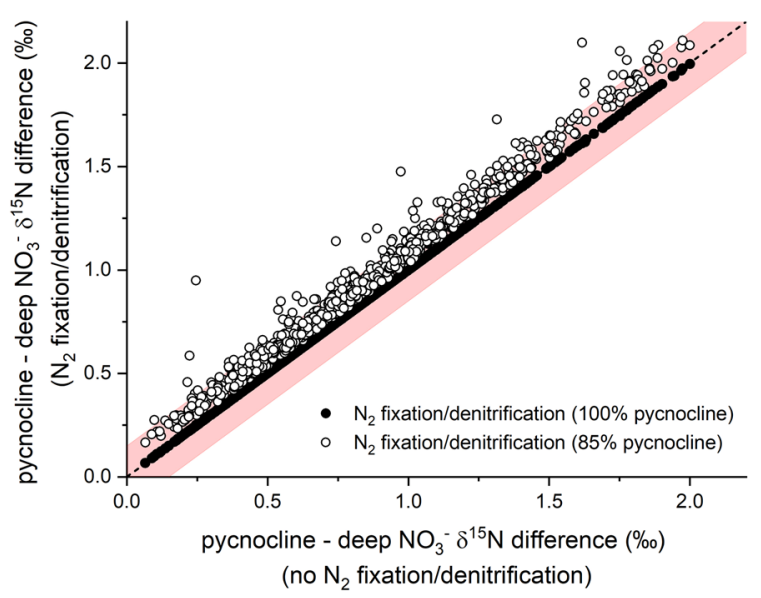

Extended Data Fig. 2 | Comparison of fixed $\mathbf{N}$ budget scenarios in the prognostic five-box ocean model. Comparison of the $\mathrm{NO}_{3}{ }^{-} \delta^{15} \mathrm{~N}$ difference between the deep ocean and the pycnocline for the model scenario without $\mathrm{N}_{2}$ fixation - denitrification and either the scenario where $20 \%$ of sedimentary denitrification (15\% of total denitrification) occurs in the deep ocean, accompanied by a balancing amount of $\mathrm{N}_{2}$ fixation (empty circles). The red envelope represents the uncertainty for the model best-fits given by the one-box model (Extended Data Figure 6c). 
ARTICLES

NATURE GEOSCIENCE

A)

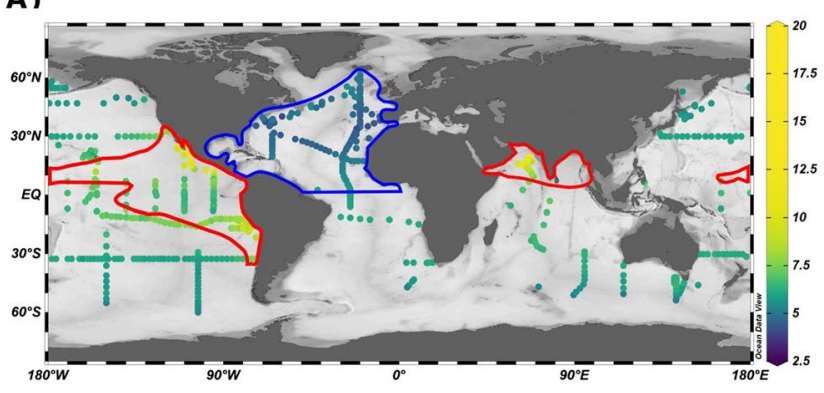

B) N. At. Rest $\mathrm{OMZ}$

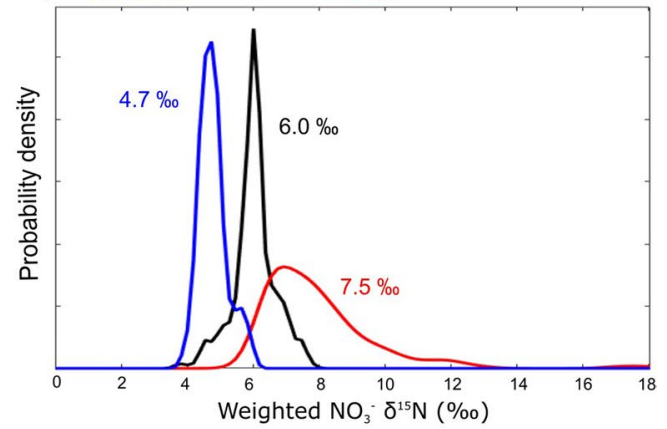

Extended Data Fig. 3 | Pycnocline weighted $\mathrm{NO}_{3}-\delta^{15} \mathrm{~N}$ per station and domain. Weighted $\mathrm{NO}_{3}{ }^{-} \delta^{15} \mathrm{~N}$ per station in the pycnocline shown on a map (A) and by measurement density (B). For the measurement density, the stations are grouped by category (defined on the map) as North Atlantic (blue contour), OMZ-influenced $\left(\mathrm{O}_{2}\right.$ concentration $<1 \mathrm{ml} \mathrm{l}^{-1}$ at the $26.8 \mathrm{~g} \mathrm{~kg}^{-1}$ isopycnal) (red contours), and the remaining stations (rest). Numbers in panel (B) are the median values by category.

NATURE GEOSCIENCE | www.nature.com/naturegeoscience 


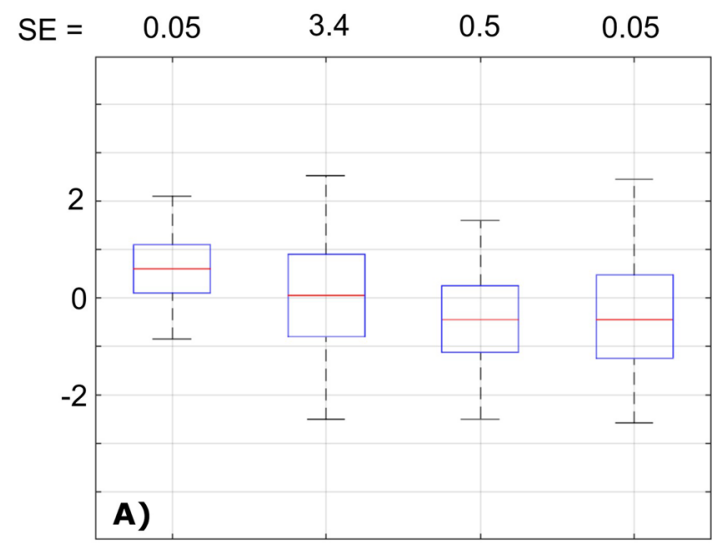

0.05
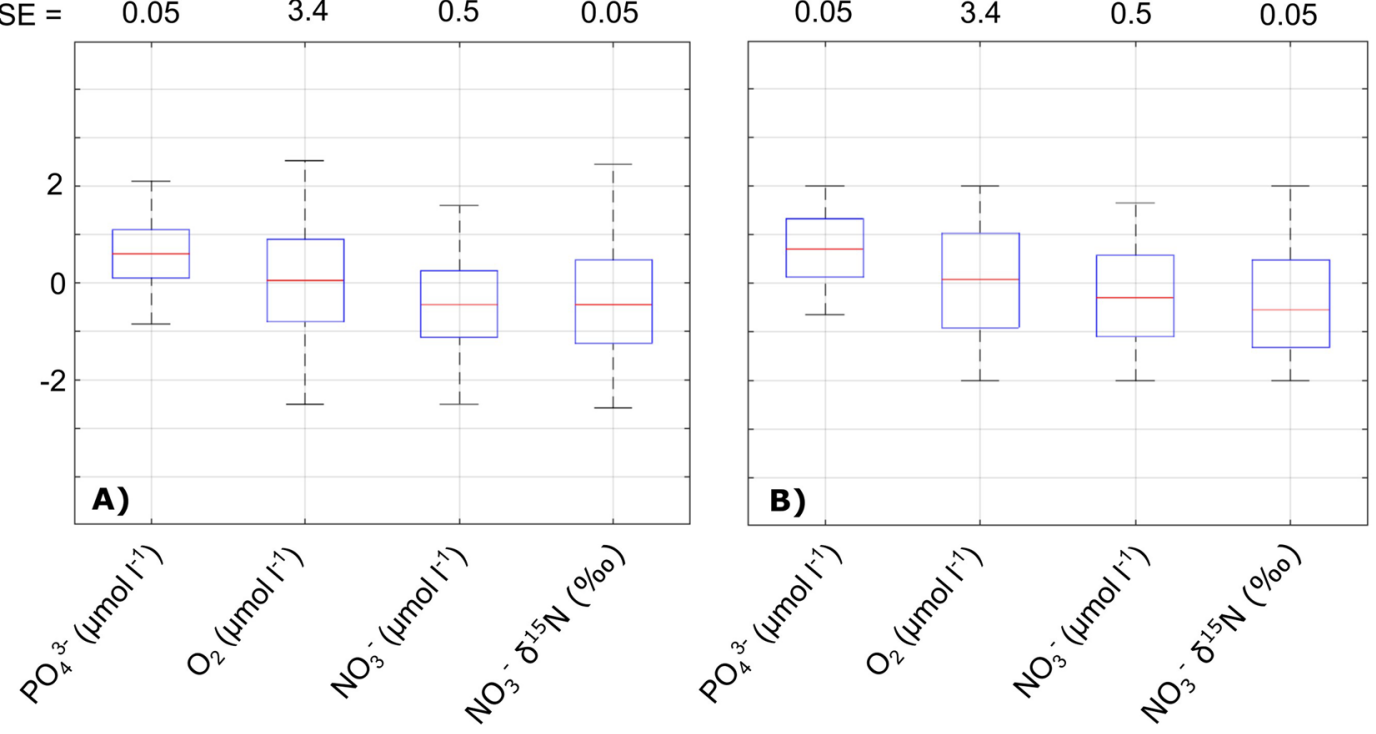

Extended Data Fig. 4 | Standardized residuals for model variables. Standardized residuals for model variables (equation 5) using the optimization scheme with RSS $<7$ (A) and by the requirement that model best fits are within two standard errors for all model variables (B). On each box, the red line indicates the median, and the bottom and top edges of the box indicate the $25^{\text {th }}$ and $75^{\text {th }}$ percentiles, respectively. The whiskers extend to the most extreme data points not considered outliers. The $y$-axis indicates the deviation between the model outputs and the observations: if equal to 0 , there is no difference between the model outputs and the observations; if equal to 2, the difference between the model outputs and the observations is two standard errors (SE). The values at the top of the panels correspond to the assigned SE for each parameter. 


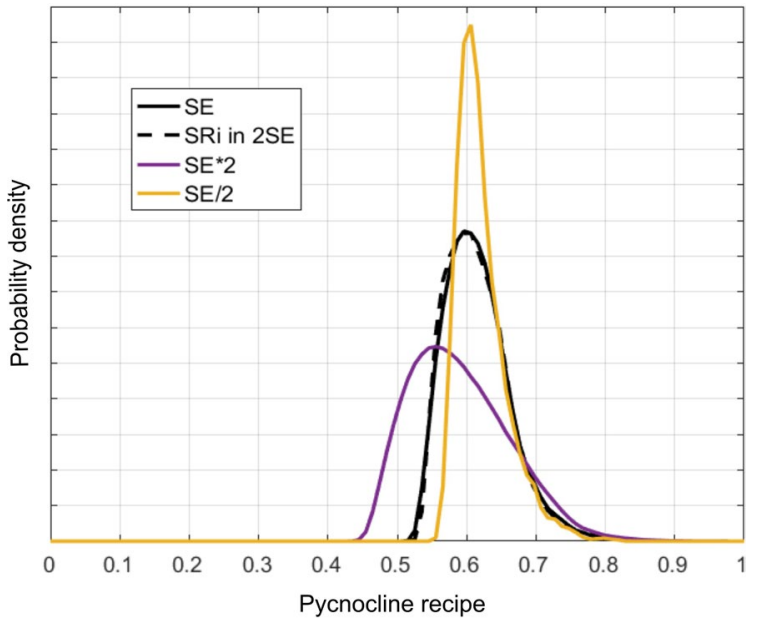

Extended Data Fig. 5 | Probability density function of the model best fits for the pycnocline recipe. The colors indicate different choices for the standard error: $\mathrm{SE}=$ standard error in the standard run (black line); $\mathrm{SE}{ }^{\star} 2=2$ times higher standard error (purple line); and SE/2 = 2 times lower standard error (orange line); SRi in 2SE = alternative optimization scheme in which a model best fit is any model scenario falling within $2 \mathrm{SE}$ of the observations for all model variables (dashed black line). 

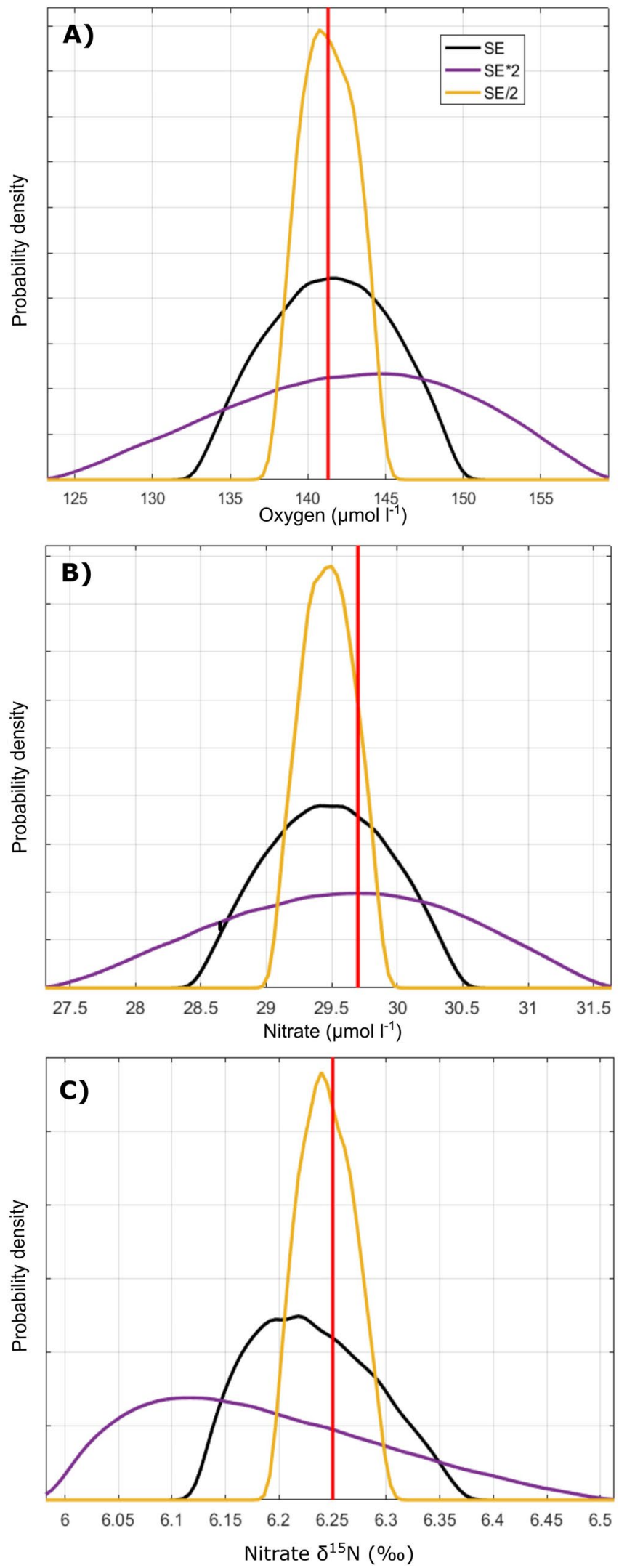

Extended Data Fig. 6 | Probability density function of the model best fits for $\mathrm{O}_{2}$ concentration, $\mathrm{NO}_{3}{ }^{-}$concentration, and $\mathrm{NO}_{3}{ }^{-} \boldsymbol{\delta}^{15} \mathrm{~N}$. The colors represent different choices for the standard error: $\mathrm{SE}=$ standard error in the standard run (black line); $\mathrm{SE}{ }^{\star} 2=2$ times higher standard error (purple line); and $\mathrm{SE} / 2=2$ times lower standard error (orange line). The vertical red bars indicate the corresponding mean weighted pycnocline values from the observations (Table 1). 
Extended Data Table 1 | Model parameters and range

\begin{tabular}{|c|c|c|c|}
\hline Parameters & Description & Range & Unit \\
\hline$\omega_{\mathbf{s}}$ & Southern Ocean overturning rates (i.e., residual) & $0-100$ & Sv \\
\hline $\mathbf{m s}_{\mathrm{s}}$ & Isopycnal mixing (i.e., eddy diffusion) & $0-100$ & Sv \\
\hline$\omega_{\mathrm{D}}$ & Interior upwelling rates & $0-100$ & Sv \\
\hline $\mathbf{m}_{\mathrm{D}}$ & Diapycnal mixing in the ocean interior & $0-100$ & Sv \\
\hline $\mathbf{y}$ & $\omega_{N-L L} / \omega_{N}$ & $0.0-1.0$ & \\
\hline $\mathbf{m}_{\mathrm{LL}}$ & Mixing with the mixed layer & $0-50$ & Sv \\
\hline $\mathbf{f}_{\phi-L L}$ & Fraction of low-lat. nutrient supply being exported with $\phi_{\mathrm{LL}}$ & 1.00 & \\
\hline$\phi \mathrm{LL}$ & Low-latitude mixed layer's export production & $46-16,297$ & $\operatorname{Tg~N~yr}{ }^{-1}$ \\
\hline$f_{R-L L}$ & Fraction of $\phi_{L L}$ being remineralized in the pycnocline & $0.8-0.9$ & \\
\hline $\mathbf{R}_{\mathrm{LL}}$ & Low-latitude remineralization & $39-14,556$ & $\operatorname{Tg~N~yr} r^{-1}$ \\
\hline$\phi$ SAZ & PFZ-SAZ's export production & $0-250$ & $\operatorname{Tg~N~yr} r^{-1}$ \\
\hline$f_{\text {R-SAZ }}$ & Fraction of $\phi_{S A Z}$ being remineralized in the pycnocline & $0.0-0.5$ & \\
\hline $\mathbf{R}_{\mathrm{SAZ}}$ & SAZ remineralization & $0-125$ & $\operatorname{Tg~N~yr}{ }^{-1}$ \\
\hline$\phi S A z \delta^{15} N$ & SAZ export production $\delta^{15} \mathrm{~N}$ & $0.5-3.0$ & $\%$ \\
\hline
\end{tabular}

